ARTICLE

\title{
Rapid evolution of bacterial mutualism in the plant rhizosphere
}

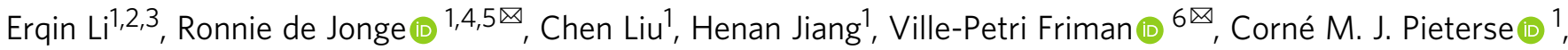
Peter A. H. M. Bakker ${ }^{1} \&$ Alexandre Jousset (1D) ${ }^{7 凶}$

While beneficial plant-microbe interactions are common in nature, direct evidence for the evolution of bacterial mutualism is scarce. Here we use experimental evolution to causally show that initially plant-antagonistic Pseudomonas protegens bacteria evolve into mutualists in the rhizosphere of Arabidopsis thaliana within six plant growth cycles (6 months). This evolutionary transition is accompanied with increased mutualist fitness via two mechanisms: (i) improved competitiveness for root exudates and (ii) enhanced tolerance to the plantsecreted antimicrobial scopoletin whose production is regulated by transcription factor MYB72. Crucially, these mutualistic adaptations are coupled with reduced phytotoxicity, enhanced transcription of MYB72 in roots, and a positive effect on plant growth. Genetically, mutualism is associated with diverse mutations in the GacS/GacA two-component regulator system, which confers high fitness benefits only in the presence of plants. Together, our results show that rhizosphere bacteria can rapidly evolve along the parasitism-mutualism continuum at an agriculturally relevant evolutionary timescale.

\footnotetext{
${ }^{1}$ Utrecht University, Department of Biology, Plant-Microbe Interactions, Utrecht, The Netherlands. ${ }^{2}$ Freie Universität Berlin, Institut für Biologie, Berlin, Germany. ${ }^{3}$ Berlin-Brandenburg Institute of Advanced Biodiversity Research, Berlin, Germany. ${ }^{4}$ VIB Center for Plant Systems Biology, Ghent, Belgium. ${ }^{5}$ Ghent University, Department of Plant Biotechnology and Bioinformatics, Ghent, Belgium. ${ }^{6}$ University of York, Department of Biology, York, UK. ${ }^{7}$ Utrecht University, Department of Biology, Ecology and Biodiversity, Utrecht, The Netherlands. ${ }^{凶}$ email: r.dejonge@uu.nl; ville.friman@york.ac.uk; A.L.C.Jousset@uu.nl
} 
M utualistic interactions between multicellular hosts and their associated microbiota are important for the fitness of both parties ${ }^{1-4}$. However, while commonly observed in nature, direct evidence for the evolution of mutualism at both phenotypic and genotypic level is still limited ${ }^{5-7}$. The rhizosphere is a hotspot for mutualistic interactions between the plant and free-living microorganisms. For example, plants can preferentially interact with mutualistic microbes present in the indigenous species pool of the soil and disproportionally increase their relative abundances in the rhizosphere ${ }^{8-10}$. While such plantmediated ecological filtering can rapidly change the relative abundances of mutualistic versus antagonistic species in the rhizosphere, it is less clear if plants can drive evolution of mutualism within species by increasing the fitness of emerging de novo mutualist genotypes. For example, even the most well-known plant mutualistic microbes, nitrogen-fixing rhizobia ${ }^{5}$ and phosphorus-providing mycorrhizae ${ }^{11}$, can be detrimental to the plant, suggesting that the interaction between a given pair of plant and microorganism varies naturally ${ }^{12,13}$. It is thus possible that plant-associated microbes might evolve along the parasitismmutualism continuum in response to selection exerted by plants.

Beneficial symbioses between eukaryotic and prokaryotic organisms have evolved multiple times across the eukaryotic domain $^{14}$ and are considered as one of the major evolutionary transitions of life ${ }^{15}$. It has been suggested that the evolution of mutualism often requires two basic components: currency and mechanism of exchange of the currency ${ }^{14}$. In the context of plant-bacteria interactions, currency could be, for example, a root exudate, which can be taken up by bacteria. Similarly, bacteria might produce plant growth-promoting hormones such as auxin and gibberellins ${ }^{16}$, which could be beneficial for plant growth. When the currency exchange between both parties is symmetrical, the selection is expected to favour the evolution of mutualism. Increased mutualistic dependence is then thought to evolve via reciprocal coevolution or via adaptation by one of the partners via selection on traits that are directly involved in the mutualistic interaction ${ }^{15}$. Currency exchange could also be asymmetrical, due to competition for shared limiting nutrients, such as iron ${ }^{17}$, which could explain why certain plant-microbe interactions are antagonistic. Moreover, due to the open nature of the rhizosphere, free diffusion of plant-derived resources could select for increased levels of cheating where mutant bacterial genotypes take advantage of 'public goods' without contributing to the production of plant growth-promoting compounds ${ }^{5,17}$. As a result, mutualistic plant-microbe interactions might require additional enforcing from the plant ${ }^{5}$ via sanctioning of cheating bacterial genotypes or by positively discriminating plant growth-promoting genotypes.

To assess whether plant-microbe mutualism can emerge as a consequence of plant-mediated effects, we apply an in vivo experimental evolution design ${ }^{18}$, allowing the rhizosphere bacterium Pseudomonas protegens CHA0 to evolve on the roots of Arabidopsis thaliana in the absence of other microbes. This is achieved using sterile sand free of organic carbon as the growth substrate. As a result, bacterial survival and evolution is solely dependent on the presence of the plant, and the performance of evolved bacterial selection lines can be quantified in comparison with the ancestral bacterial strain. To set up the selection experiment, a clonal ancestral $P$. protegens bacterial population is inoculated on the roots of five independent $A$. thaliana Col-0 replicate plants (i.e., five plant replicate selection lines) and plants and bacteria grown in otherwise gnotobiotic conditions for a total of six plant growth cycles (each cycle lasting for 4 weeks). At the end of every growth cycle, the evolved bacterial populations are isolated and transferred to the rhizosphere of new sterile plants (Fig. S1). As a result, only bacteria are let to evolve, and the plant genotype is kept constant throughout the selection experiment. In these experimental conditions, the initial plant-bacterium interaction is antagonistic: A. thaliana aboveground biomass is reduced in the presence of $P$. protegens $\mathrm{CHA} 0$ after one growth cycle $\left(F_{1,8}=45.4, P<0.001\right.$, Fig. 1a), and a likely cause for this is the production of diverse bioactive metabolites by $\mathrm{CHA} 0^{19}$ that can constrain plant growth ${ }^{20}$. To quantify changes in plant-bacterium interaction, 16 evolved bacterial colonies are randomly selected from each plant replicate selection line at the end of the second, fourth and sixth growth cycles, in addition to 16 randomly selected ancestral colonies (in total, 256 isolates). Each isolated colony is characterized phenotypically by measuring multiple key life-history traits, including growth on different carbon sources and media, tolerance to diverse abiotic and biotic stresses, production of several bioactive compounds and their ability to inhibit other microorganisms (Table S1). A subset of bacterial phenotypes is also subjected to full genome sequencing and characterized for their effects on plant growth in terms of root architecture, above and belowground biomasses, and activation of the root-specific transcription factor gene MYB72 at the end of the selection experiment. The overall results illustrate that $P$. protegens rapidly diversifies into mutualist genotypes that have positive effects on the plant growth and competitive advantage over ancestral genotypes in the rhizosphere.

\section{Results}

Selection in the plant rhizosphere leads to bacterial phenotypic diversification and evolutionary transition towards mutualism. To study the evolution of $P$. protegens $\mathrm{CHA} 0$ in the A. thaliana rhizosphere, we isolated a total of 240 evolved bacterial isolates from every second time point along with sixteen ancestral isolates (Supplementary Data 1 ) and used $K$-means clustering analysis to separate them into five distinct phenotypic groups based on several life-history traits (Fig. S2 and Table S2). The phenotypic groups were then given names that reflected key differences in their lifehistory traits and their mean effects on plant growth (Fig. 1 and Figs. S3 and S4). Evolved clones that clustered together with the ancestral strains were named as 'Ancestral-like' phenotype. Another phenotype similar to the ancestral strain, which only appeared momentarily before dropping below detection level, was named as 'Transient' phenotype (Figs. 1 and 2). A third phenotype that had clearly reduced abiotic stress tolerance $\left(F_{5,248}=40.8, P<\right.$ 0.001 , Fig. S4) and increased ability to form a biofilm $\left(F_{5,249}=\right.$ 196.8, $P<0.001$, Fig. S4) was named as 'Stress-sensitive' phenotype. Agar plate assays were used to determine the effect of the evolved phenotypes on A. thaliana growth. While the 'Ancestral-like', 'Transient' and 'Stress-sensitive' phenotypes showed neutral effects on plant biomass relative to plant-only controls (shoot biomass, $F_{6}$, ${ }_{26}=8.01, P<0.001$; root biomass, $F_{6,26}=2.84, P=0.029$, Fig. 1 ), they had a negative effect on the plant root length (root length, $F_{6}$, ${ }_{26}=10.01, P<0.001$, Fig. $1 \mathrm{~d}$ ) and caused a clear bleaching of plants indicative of reduced chlorophyll activity similar to the ancestral strain (the amount of green pixels, $F_{6,26}=5.90, P<0.001$, Fig. $1 \mathrm{f}$ ). These assays also revealed two novel phenotypes that showed positive effects on plant shoot and root biomasses (Fig. 1b, c) with comparable levels of plant 'greenness' to plant-only controls (Fig. 1f). These evolved phenotypes were therefore named as 'Mutualist 1' and 'Mutualist 2'as indicated by their plant growthpromoting activity.

The relative abundance of different phenotypic groups changed over time (Fig. 2a). The 'Ancestral-like' phenotypes persisted throughout the experiment even though they were substituted by evolved phenotypes in all plant selection lines (Fig. 2a). The evolutionary success of 'Transient' and 'Stress-sensitive' phenotypes was generally short-lived: 'Transient' phenotypes disappeared below the detection limit in all plant selection lines by the 
a

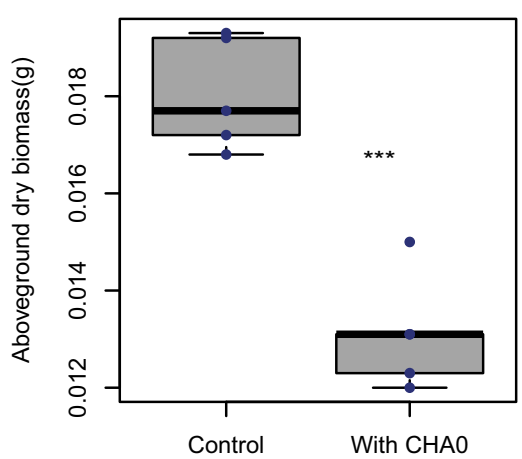

d

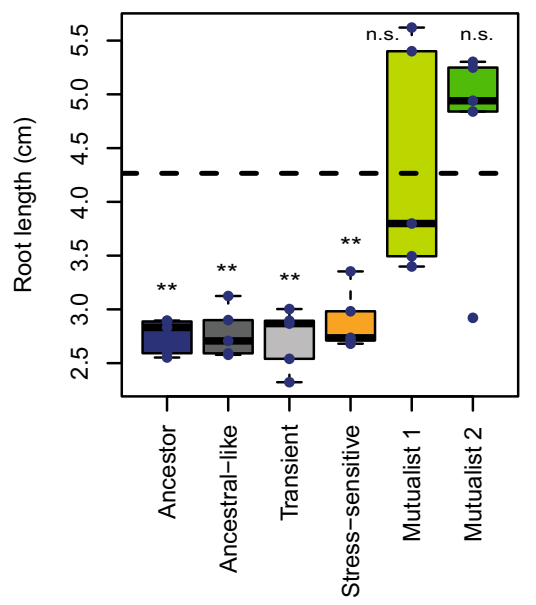

b

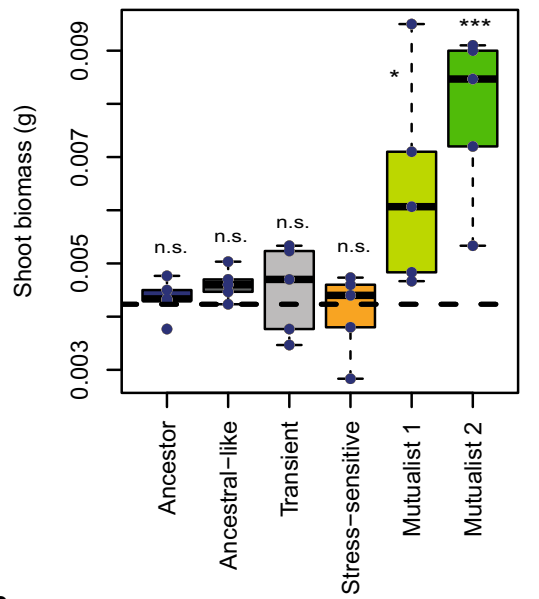

e

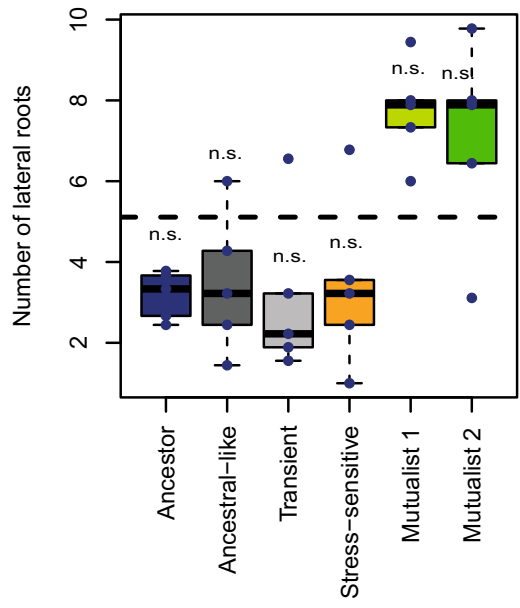

C

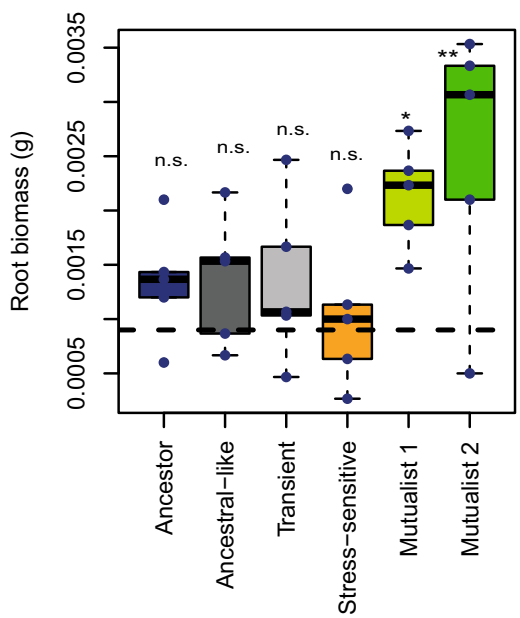

$\mathbf{f}$

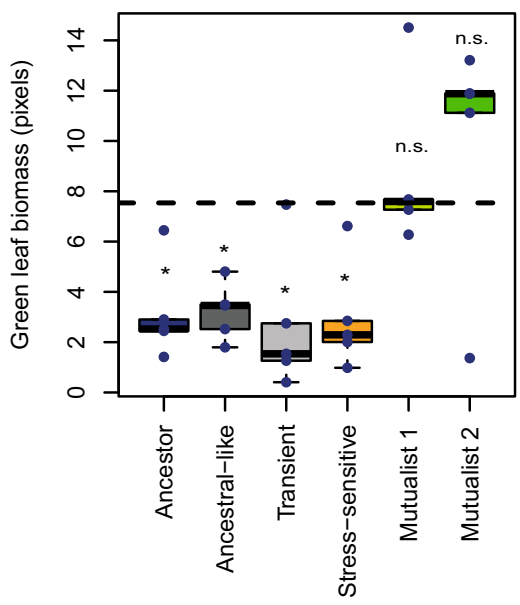

Fig. 1 Evolution of bacterial mutualism in the rhizosphere of Arabidopsis thaliana. Panel a shows the initially antagonistic effect of $P$ seudomonas protegens $\mathrm{CHAO}$ on $A$. thaliana after one plant growth cycle in the sterile sand study system $\left(n=5\right.$; aboveground biomass $\left.{ }^{\star \star \star} P=0.0001\right)$. Panels $\mathbf{b}-\mathbf{f}$ compare the effects of ancestral and evolved Pseudomonas protegens $\mathrm{CHAO}$ phenotypes on plant performance-related traits in a separate plant growth assays performed on agar plates at the end of the selection experiment ( $n=3$ for control and $n=5$ for each evolved phenotype, see Table S2). Different panels show the shoot biomass in grams (b), root biomass in grams (c), number of lateral roots (d), root length in $\mathrm{cm}(\mathbf{e})$, and the amount of plant 'greenness' in terms of green-to-white pixel ratio (f) after 14 days of bacterial inoculation (Supplementary Data 2; blue dashed horizontal lines show the non-inoculated control plants). Bacterial phenotype groups are displayed in different colours (black: ancestor; dark grey: ancestral-like; light grey: transient; orange: stresssensitive, light green: mutualist 1 and dark green: mutualist 2) and were classified and named based on K-means clustering (Fig. S1) using 14 phenotypic traits linked to growth, stress tolerance, production of bioactive compounds and antimicrobial activity (Table S1). All boxplots show median (centre line), interquartile range (25-75\%) and whiskers that extend 1.5 times the interquartile range overlaid with a scatter plot showing independent replicates. Statistical testing in all panels was carried out using one-way ANOVA, and asterisks above plots indicate significant differences between control and bacteria-treated plants $\left({ }^{\star} P=0.05,{ }^{\star \star} P=0.01,{ }^{\star \star \star} P=0.001 ;\right.$ n.s. $=$ non-significant). Data for all panels are provided in the Source Data file.

end of the sixth growth cycle (Fig. 2a), while the 'Stress-sensitive' phenotypes emerged only in three selection lines and survived until the end of the experiment only in one of the selection lines (Fig. 2a). In contrast, the frequency of mutualistic phenotypes increased in four out of five plant selection lines throughout the experiment, while one selection line became dominated by 'Ancestral-like' and 'Stress-sensitive' phenotypes (Fig. 2a).

An aggregated 'plant performance' index summarising the effects of each bacterial isolate on both aboveground and belowground plant growth traits (Fig. 2b, PC1 of multivariate analysis) was used to explore if reduced antagonism towards the plant was associated with improved bacterial growth indicative of the evolution of a reciprocally beneficial mutualistic interaction. We found a significant positive correlation between plant performance index and bacterial phenotype abundance per plant $\left(F_{1,28}=8.01, P<0.001\right.$, Fig. $\left.2 c\right)$. Specifically, both mutualistic phenotypes reached higher abundances in the plant rhizosphere compared to other phenotypes (bacterial cells per plant). This indicates that reduced bacterial antagonism towards the plant was coupled with improved growth in the rhizosphere, which could also explain why mutualists became the dominant phenotypes in four out of five plant selection lines during the selection experiment (reaching up to $94 \%$ relative abundance, Fig. 2a). In support for this, a similar positive correlation was observed between the degree of plant performance of each phenotype measured in separate plant growth assays and their relative abundance in diversified rhizosphere populations at the end of the selection experiment $\left(F_{1}, 23=4.37, P=0.048\right.$, Fig. S5). Together, these results demonstrate that the evolution of plantgrowth promotion was accompanied with increased bacterial fitness, indicative of a mutualistic interaction where each species had a net benefit. As this evolutionary transition was observed in 
a
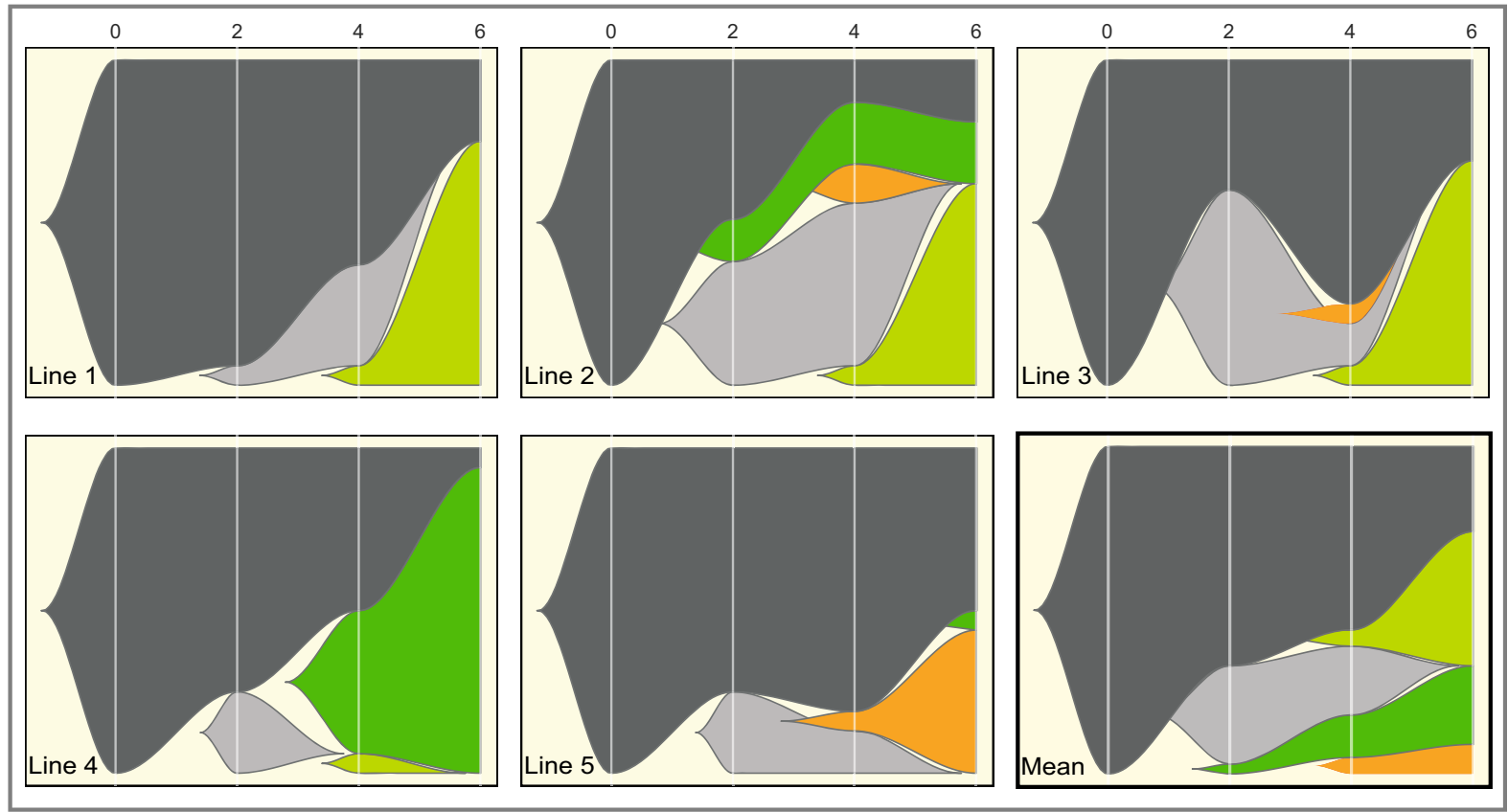

b

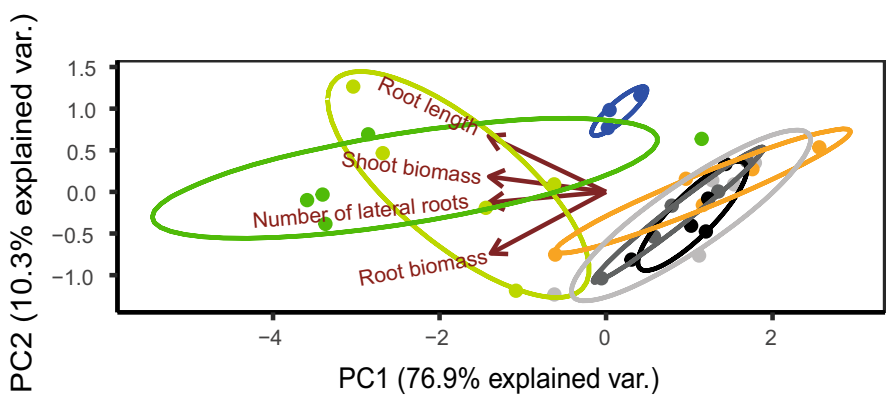

Color code

\begin{tabular}{llll}
\hline - Ancestor & Transient & Mutualist 2 \\
- Ancestral-like & - Mutualist 1 & Stress-sensitive $\quad$ Control
\end{tabular}

C

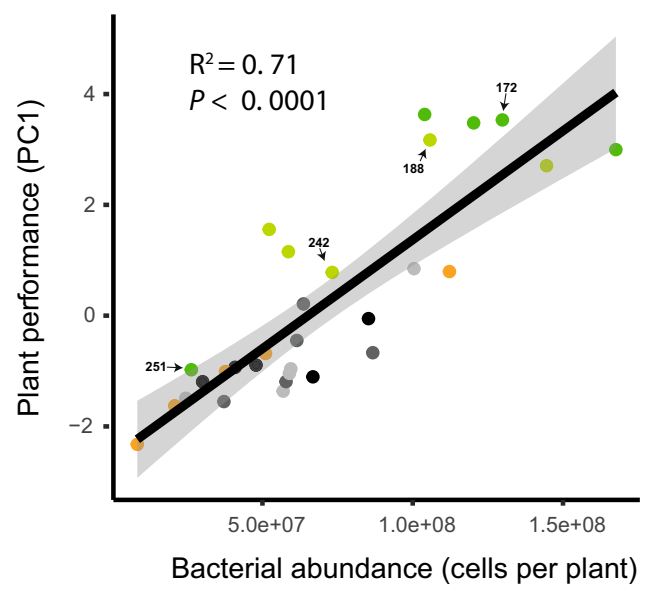

Fig. 2 Temporal changes in bacterial phenotypes during the selection experiment and positive correlation between evolved bacteria and plant growth. Panels in a show the dynamics of five bacterial phenotype groups across five plant replicate lines and the overall mean pattern during six growth cycles ( 6 months). The $x$-axis shows the plant growth cycle ( 0 : ancestral bacterium) and the $y$-axis shows the relative abundance of each bacterial phenotype. Panel $\mathbf{b}$ shows a principal component analysis (PCA) for five representative bacterial isolates from each evolved phenotype group in addition to ancestor isolates (see Table S2) based on their plant growth-related traits. The negative PC1 values of each isolate were extracted and combined to a 'Plant performance' index, which included bacterial effects on shoot biomass, root biomass and root architecture explaining $76.9 \%$ of the total variation in plant growth. Panel c shows a positive correlation between 'Plant performance' and bacterial abundance on the plant roots at the end of the fitness assays; the black line and grey area indicate the linear regressions with 95\% confidence intervals, respectively $(n=30$, biologically independent isolates, see Table S2; $P=4.296 \mathrm{e}-09$ ). In all panels, bacterial phenotype groups are displayed on different colours (black: ancestor; dark grey: ancestral-like; light grey: transient; orange: stress-sensitive, light green: mutualist 1 and dark green: mutualist 2). The sample IDs of four isolates from the two mutualistic phenotype groups are highlighted on labels. Data for all panels are provided in the Source Data file.

parallel in four out of five selection lines, it was likely driven by deterministic processes such as selection exerted by the plant or bacterial competitive superiority instead of random genetic drift due to bottlenecking between plant growth cycles.

Evolution of mutualism is linked to improved resource catabolism and tolerance to plant-secreted antimicrobials. For stable mutualism to evolve, plants would need to provide the evolved mutualists a 'currency' that could not be accessed by the other phenotypes or employ some form of 'sanctioning' to constrain the growth of non-mutualist phenotypes. To study this, we first compared differences in the evolved phenotypes' ability to use a range of carbon sources that are typically found in $A$. thaliana root exudates ${ }^{21}$, and which could have selectively preferred the growth of mutualist phenotypes. Second, we compared the evolved phenotypes' tolerance to scopoletin, which is an 
a

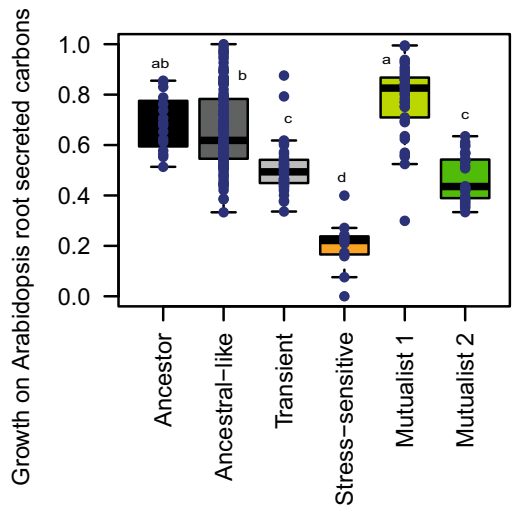

d

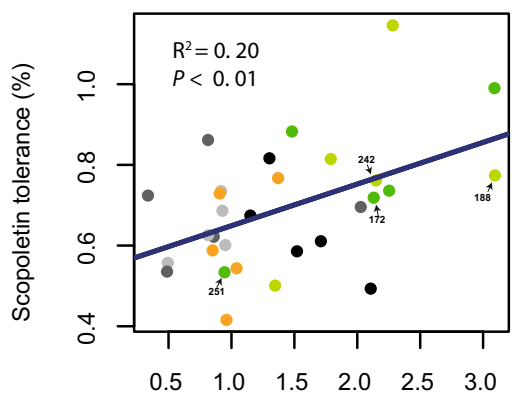

Fold induction of MYB72 b
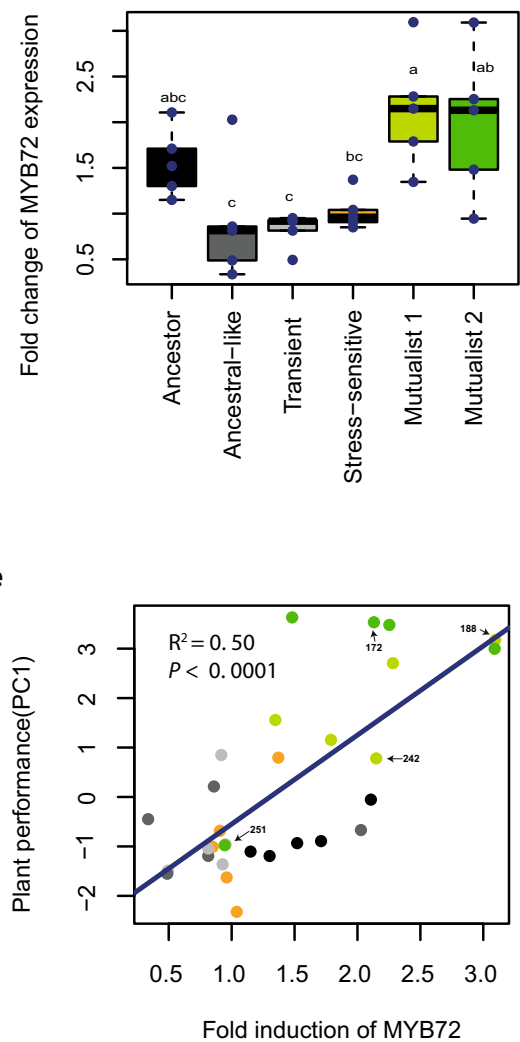

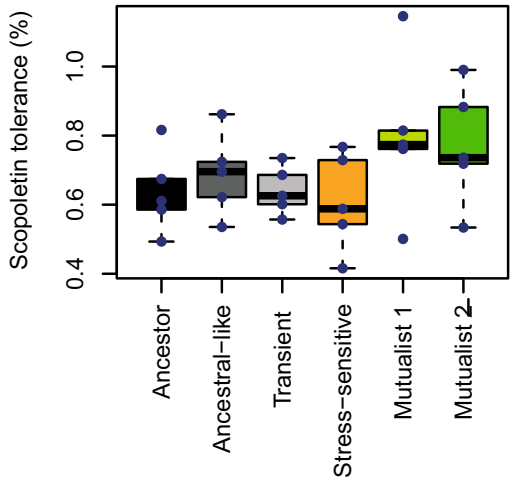

f

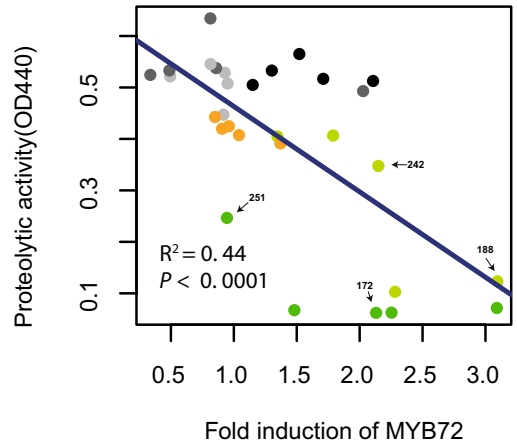

Fig. 3 Selection mechanisms favouring the increase in the relative abundance of mutualists in the rhizosphere of Arabidopsis thaliana. Panel a shows the growth of ancestor and evolved Pseudomonas protegens $\mathrm{CHAO}$ phenotypes on carbons typically secreted by $\mathrm{A}$. thaliana (14 most dominant carbons analysed as a combined index based on normalised first principal component PC1, which explained $83.9 \%$ of total variation). In total, 256 isolates were characterized including ancestral $(n=16)$, 'Ancestral-like' $(n=119)$, 'Transient' $(n=41)$, 'Stress-sensitive' ( $n=11)$, 'Mutualist 1 ' (37), and 'Mutualist 2' ( $n$ =31) phenotypes. Panel $\mathbf{b}$ shows the effect of ancestor and evolved $P$. protegens CHAO phenotypes on the expression of $M Y B 72$ (transcription factor responsible for scopoletin production) in the roots of a GUS A. thaliana reporter line (based on the quantification of GUS staining of the roots, Fig. S6). Panel c shows the relative growth of ancestor and evolved $P$. protegens $\mathrm{CHAO}$ phenotypes in the presence of the plant-secreted scopoletin antimicrobial at $2 \mathrm{mM}$ concentration after $72 \mathrm{~h}$ of incubation relative to no-scopoletin control. Panel d shows a positive relationship between $\mathrm{MYB} 72$ expression (fold induction; $x$-axis) and scopoletin tolerance ( $y$-axis) for all tested isolates. Panel e shows a positive relationship between $M Y B 72$ expression (fold induction; $x$-axis) and plant performance ( $y$-axis) for all tested isolates. Panel $\mathbf{f}$ shows a negative relationship between $M Y B 72$ expression (fold induction; $x$-axis) and proteolytic activity ( $y$-axis) for all tested isolates. The sample IDs of four isolates from the two mutualistic phenotype groups are highlighted on labels (see Table S2) in panels d-f. Panels b-f include five representative bacterial isolates ( $n=5$, biologically independent isolates) from each phenotype in addition to the ancestor (each replicate line represented; see Table S2). In all panels, bacterial phenotype groups are displayed on different colours (black: ancestor; dark grey: ancestral-like; light grey: transient; orange: stress-sensitive, light green: Mutualist 1 and dark green: Mutualist 2). All boxplots show median (centre line), interquartile range (25-75\%) and whiskers that extended 1.5 times the interquartile range overlaid with a scatter plot showing independent replicates. Statistical testing in panels a-c was carried out using one-way ANOVA followed by Tukey's multiple comparison test ( $\alpha=0.05$; different lowercase letters indicate significant differences). Panels $\mathbf{d - f}$ show linear regression (black line) and Pearson correlations fitted over all biologically independent isolates $(n=30)$. Data for all panels are provided in the Source Data file.

antimicrobial secreted by plant roots known to modulate the composition of the root-associated microbial community by favouring more tolerant bacterial taxa ${ }^{22,23}$. We found that the 'Mutualist 1' phenotypes showed an improved ability to grow on various carbon sources typical for $A$. thaliana root exudates compared to the other phenotypes (PC1 of multivariate analysis, $F_{5,249}=46.67, P<0.001$, Fig. 3a). Moreover, 'Transient', 'Stresssensitive' and 'Mutualist 2' phenotypes showed reduced growth on carbon sources relative to 'Ancestral-like' phenotypes indicative of competitive disadvantage (Fig. 3a). These results suggest that 'Mutualist 1' phenotypes potentially evolved to be better at competing for plant-derived root exudates, which could have increased their abundance relative to other phenotypes.

To explore the potential significance of the antimicrobial scopoletin, we used a GUS reporter assay to determine how different bacterial phenotypes affected the expression of the plant root-specific transcription factor gene $M Y B 72^{24}$, which encodes a known positive regulator of scopoletin biosynthesis ${ }^{22}$. We found that plants inoculated with 'Mutualist 1' and 'Mutualist 2' phenotypes retained high GUS activity, which was comparable to the ancestor $\left(F_{5,24}=5.6, P<0.01\right.$, Fig. $3 \mathrm{~b}$ and Fig. S6). However, the other evolved phenotypes induced a reduced GUS activity in plants relative to the mutualists (Fig. $3 \mathrm{~b}$ and Fig. S6). While the 'Mutualist 1' and 'Mutualist 2' phenotype groups included strains that showed very high tolerance to scopoletin, their mean tolerance did not significantly differ from other phenotype groups $\left(F_{5,24}=1.76, P=0.16\right.$, Fig. $\left.3 c\right)$. However, a significant positive correlation was observed between the induction of MYB72 in A. thaliana roots and phenotypes' tolerance to scopoletin $\left(F_{1,28}=\right.$ 8.29, $P<0.01$, Fig. $3 \mathrm{~d}$ ). This suggest that both the activation of scopoletin production and the scopoletin tolerance were potentially under co-selection as the only mutualistic phenotypes 
showing high scopoletin tolerance were those able to upregulate the expression of $M Y B 72$, a gene positively regulating scopoletin production by the plant. Such mechanism could have ensured positive selection for scopoletin-inducing, scopoletin-tolerant mutualists relative to other evolved phenotypes. We also found that MYB72 induction was positively correlated with plant growth (i.e., plant performance, Fig. 3e) and negatively correlated with phytotoxic compounds (i.e., exoprotease production, Fig. 3f). Moreover, scopoletin tolerance was positively correlated with both plant performance (Fig. S6A) and bacterial fitness on the plant roots (Fig. S7A). Together, these results suggest that both mutualists had positive effects on the plant growth, and that plants could positively discriminate mutualist phenotypes by providing specific 'nutrient' and 'tolerance' niches, creating a positive feedback loop.

Mutualistic phenotypes had mutations in genes encoding the GacS/GacA two-component regulatory system. To gain insights into the genetic mechanisms underlying the evolution of mutualism, we performed whole-genome re-sequencing of 30 isolates followed by reference-based identification of single-nucleotide polymorphisms (SNPs) and small and large insertions or deletions (INDELs). Because bacterial populations consisted only of one bacterial species, and as no plasmids or large genomic islands have been detected in the $P$. protegens CHA0 genome, we excluded the potential role of mobile genetic elements in explaining the phenotypic variation ${ }^{25}$. These analyses revealed that different evolved bacterial phenotypes were associated with relatively few mutations in global regulator genes (Fig. 4), underpinning their central role in bacterial adaptation ${ }^{26,27}$. While only a few non-parallel mutations were observed in case of 'Ancestral-like' and 'Transient' phenotypes (Table S2), all but two mutualistic isolates $(8 / 10)$ harboured mutations in genes encoding the GacS/GacA two-component system, which regulates secondary metabolism alongside many other aspects of bacterial physiology ${ }^{28}$. Despite a high level of parallelism, a variety of different mutations were observed within the gacS and gacA genes. Three gacS/gacA mutations were unique to 'Mutualist 1 ' isolates, and specifically associated with an uncharacterized $\mathrm{N}$ terminal histidine kinase domain in GacS (G27D) and the response regulatory domain of GacA (G97S; D49Y, Fig. 4 and Table S2). Three unique 'Mutualist 2' mutations were found inside the gacA coding region (E38X, D54Y and Y183S, Fig. 4 and Table S2). Mutations upstream the transcription start site $(-40$ nucleotides), potentially representing a promoter binding site, were detected within both mutualists (Table S2). The conserved phosphate-accepting aspartate 54 (D54) residue is important for phospho-relay initiated by the sensor kinase GacS, and mutations of this residue are associated with complete loss-of-function ${ }^{29-31}$. Aspartate 49 (D49) is another conserved residue in the vicinity of D54, and the gacA (49Y) allele has previously been reported to be associated with a partial reduction in GacA activity ${ }^{31}$. The other mutations in $g a c A$ are novel and conceivably have a significant impact on GacA activity as they result in a severely truncated protein (E38X) or are located within the third recognition helix of the LuxR-like tetra-helical helix-turn-helix (HTH) domain, which is known to make most of the DNA contacts (Y183S) ${ }^{32}$. In line with the predicted effects of the mutations, 'Mutualist 1' isolates retained part of the GacS/GacA-mediated traits, while 'Mutualist 2 ' isolates showed a severe to complete disruption of extracellular proteolytic and antifungal activity (Fig. S3). Interestingly, 'Mutualist 1' isolates with mutations in gacS (G27D) and gacA (D49Y) both showed a lower plant performance compared to other gac mutants. Moreover, a single mutation in the fleQ (R320Q) gene was found in mutualist ID251 (line 5), with no clear link with plant performance (Fig. 4a), while a mutation in the $\operatorname{accC}(\mathrm{E} 413 \mathrm{~K})$ gene was identified in certain mutualistic isolates with positive effect on plant performance (Fig. 4a). The gene accC encodes the biotin decarboxylase subunit of the acetyl coenzyme A carboxylase complex involved in fatty acid biosynthesis and its role on bacterial physiology and bacteria-plant interactions should be validated in the future. Together, these differences between individual mutations are likely to explain the observed variation in life-history traits (including plant performance) within and between the 'Mutualist 1' and 'Mutualist 2' groups.

Interestingly, while mutualists emerged in all plant replicate selection lines, they did not become the dominant phenotype in selection line 5 . Instead, this selection line became dominated by 'Stress-sensitive' bacteria (Figs. 1 and 4), which also transiently appeared in two other plant selection lines. Genetically, the 'Stress-sensitive' phenotype was mainly associated with mutations in the $r s m Y$ region in $P$. protegens $\mathrm{CHA} 0^{33}$ including nonsynonymous mutations in $n l p D(\mathrm{Q} 197 \mathrm{P})$ and $r p o S(\mathrm{Q} 65 \mathrm{X})$. NlpD encodes a lipoprotein predicted to play a role in cell wall formation and cell separation and is found immediately upstream of rpos. The rpoS gene encodes sigma factor $\sigma^{38}$, which mediates general stress resistance ${ }^{34,35}$, downregulates the biosynthesis of antagonistic secondary metabolites ${ }^{36}$ and is involved in biofilm formation $^{37}$ in several bacterial taxa. In line with this, we found that 'Stress-sensitive' phenotypes were able to form high amounts of biofilm in vitro (Fig. S4), which may have supported more efficient root colonization ${ }^{38}$, explaining their dominance. More efficient root colonization could have further initiated a strong priority effect ${ }^{39,40}$, potentially constraining the subsequent emergence of mutualistic bacterial phenotypes within the time frame of the experiment. Mutations in $n l p D$ has been linked to alterations in colony morphology, possibly through changes in the expression of $r p o S$ as $n l p D$ has been found to exert a promoter function on rpoS in Escherichia colit and Pseudomonas aeruginos $a^{42}$. One of the sequenced 'Stress-sensitive' clones had also a mutation in a TetR-family transcriptional regulator (tetR). Interestingly, this mutation had a tentative epistatic effect on rpoS as indicated by the relatively stronger, but non-significant, effect of the rpoS.tetR double mutant on plant performance. Notably, the TetR-family regulator PsrA was previously reported to regulate the expression of rpoS in Pseudomonas spp. ${ }^{42}$, further strengthening these observations. Together, these results show that while plant selection can lead to a high level of parallel evolution both at the phenotypic and molecular level, alternative evolutionary trajectories are also possible.

The fitness benefits of $\mathrm{GacS} / \mathrm{GacA}$ mutations are specific to the rhizosphere environment. In order to assess whether the observed mutations specifically conferred an advantage in the rhizosphere environment, we compared the fitness of evolved mutualists on plant roots and in liquid growth culture media. To this end, the fitness of two evolved gacA (Mutualists 1 and 2; ID 242 and ID 220, respectively, Table S2), and one gacS genotype (Mutualist 1, ID 222, Table S2) was compared relative to their direct ancestral genotypes without gac mutations (ID 133, ID 28 and ID 66, respectively, Table S2) within the same plant selection lines. Fitness was determined as the relative competitive fitness in direct pairwise competitions as a deviation from the initial 1:1 ancestor-to-successor ratio in vivo on $A$. thaliana roots and in vitro in Kings' $B(\mathrm{~KB})$, lysogeny broth (LB) and tryptic soy broth (TSB) growth media. Post-competitive genotype ratios were determined using PCR-based high-resolution melting profile (RQ-HRM) analysis (see 'Methods' and Supplementary Fig 7). It was found that all three gacS/gacA mutants had a higher fitness in 


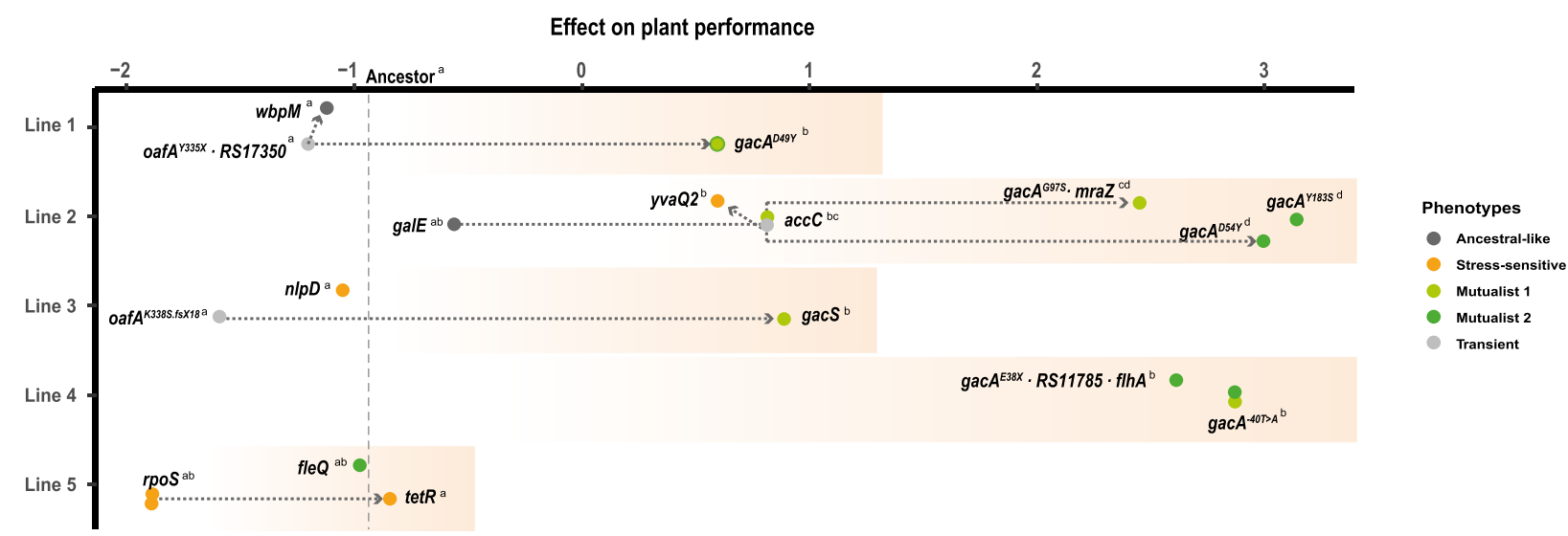

b

\begin{tabular}{|c|c|c|c|}
\hline Bacterial phenotype & Plant replicate line & Mutation & Protein function \\
\hline \multirow{5}{*}{ Mutualist 1} & \multirow[t]{2}{*}{ Line 1} & $\operatorname{gacA}(\mathrm{D} 49 \mathrm{Y})$ & Two-component regulator \\
\hline & & $\operatorname{gacA}(\mathrm{G} 97 \mathrm{~S})$ & Two-component regulator \\
\hline & \multirow[t]{2}{*}{ Line 2} & mraZ (upstream(221bp)) & Transcriptional regulator MraZ \\
\hline & & $\operatorname{accC}(\mathrm{E} 413 \mathrm{~K})$ & Biotin carboxylase \\
\hline & Line 3 & $\operatorname{gacS}(\mathrm{G} 27 \mathrm{D})$ & Two-component regulator \\
\hline \multirow{7}{*}{ Mutualist 2} & \multirow{2}{*}{ Line 2} & $\operatorname{gacA}(\mathrm{Y} 183 \mathrm{~S})$ & Two-component regulator \\
\hline & & $\operatorname{gacA}(\mathrm{D} 54 \mathrm{Y})$ & Two-component regulator \\
\hline & \multirow{4}{*}{ Line 4} & gacA (upstream (40 bp)) & Two-component regulator \\
\hline & & $\operatorname{gacA}(\mathrm{E} 38 \mathrm{X})$ & Two-component regulator \\
\hline & & $R S 11785(\mathrm{~S} 256 \mathrm{C})$ & LysR family transcriptional regulator \\
\hline & & fihA (H393Q.fs X15) & Flagellar biosynthesis protein FlhA \\
\hline & Line 5 & $f l e Q(R 320 Q)$ & Sigma-54-dependent Fis family transcriptional regulator \\
\hline \multirow{4}{*}{ Stress-sensitive } & Line 2 & yvaQ2 (upstream (9 bp )) & Methyl-accepting chemotaxis protein \\
\hline & Line 3 & $n / p D$ (Q197P) & LysM, promotor for rpos \\
\hline & \multirow{2}{*}{ Line 5} & $\operatorname{rpos}(\mathrm{Q} 65 \mathrm{X})$ & Sigma-38, stress regulon \\
\hline & & $\operatorname{tetR}(\mathrm{Y} 127 \mathrm{X})$ & TetR family transcriptional regulator \\
\hline
\end{tabular}

Fig. 4 Genetic basis of bacterial evolution in the rhizosphere of Arabidopsis thaliana. Panel a shows clear parallel evolution between four out of five plant replicate selection lines based on re-sequencing of 25 evolved and five ancestor isolates used in the phenotypic assays. Filled dots represent isolates with novel mutations (present in 18/25 evolved isolates). The seven isolates without mutations, or only synonymous mutations, are not included. The $x$-axis shows a combined index of 'Plant performance' relative to non-inoculated control plants (values on the $x$-axis indicate positive and negative effects on the plant and the $y$-axis shows the five independent plant replicate selection lines). The effect of the ancestral bacterial genotype on plant performance is shown as a vertical dashed line. Statistical testing in panel a was carried out using one-way ANOVA (each line analysed separately). The different letters on the top right of each genotype indicate significant differences based on a Tukey's HSD test $(\alpha=0.05$; each line analysed separately, $n=3)$. Bacterial phenotype groups are displayed on different colours (black: ancestor; dark grey: ancestral-like; light grey: transient; orange: stress-sensitive, light green: Mutualist 1 and dark green: Mutualist 2) and the accumulation of mutations within replicate lines are shown with connected dashed arrows. Panel $\mathbf{b}$ table lists unique mutations linked with evolved bacterial phenotypes. Successive mutations that appeared within the same genetic background are shown after the indent. Notably, these additional mutations did not affect the bacterial phenotypes (see Table S3 for a more detailed description of the mutations). Data for all panels are provided in the Source Data file.

the rhizosphere relative to their direct ancestral genotypes without gac mutations $\left(F_{3,32}=10.03, P<0.001\right.$, Fig. 5). Interestingly, this advantage was smaller for one of the gacA mutants (ID 220, $F_{2,6}=15.35, P=0.004$, Fig. 5) likely because its direct ancestor already showed mutualistic behaviour due to a mutation in the acc $C$ gene, reducing the relative benefit of the gacA mutation within this lineage (Table S2). While the fitness benefits of gac mutations were mainly observed in the rhizosphere, two gac mutants showed improved competitive fitness in $\mathrm{KB}$ media indicative of general metabolic adaptations (genotype $\times$ measurement environment: $F_{6,24}=13.02, P<0.001$; genotype comparisons in $\mathrm{KB}$ media: $\left.F_{2,6}=162.6, P<0.001\right)$. Together, these results confirm that the genetic changes underlying the evolution of bacterial mutualism were mainly beneficial in the presence of plants.

\section{Discussion}

Even though beneficial plant-microbe interactions are widely documented, their evolutionary origin is less well understood. Here we studied how an initially antagonistic relationship between the $P$. protegens $\mathrm{CHA} 0$ bacterium and its host plant, $A$. thaliana, changed during prolonged selection over six plant growth cycles (6 months). While several studies have previously reported beneficial effects of CHA0 on plant growth in natural soils, it initially showed antagonism towards the plant in our 

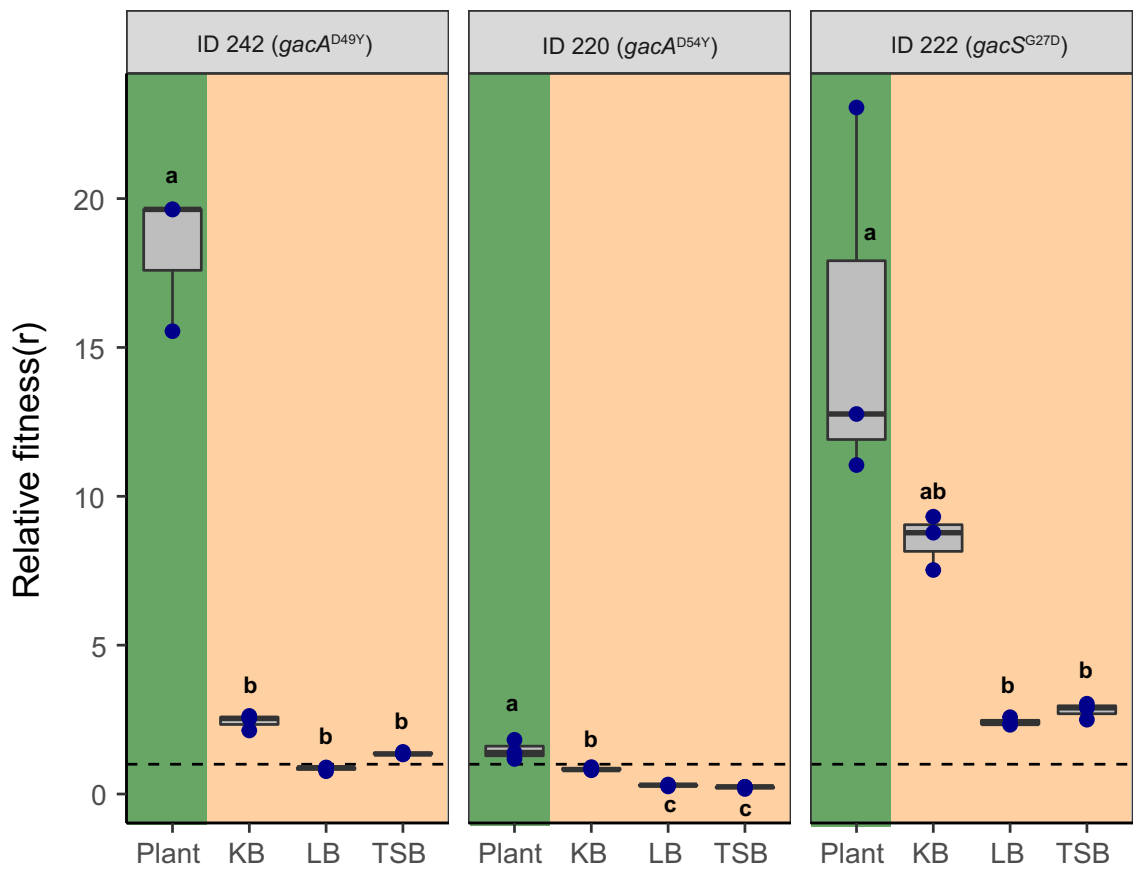

\section{Context}

Fig. 5 Competitive fitness of gac mutants relative to their direct ancestors in the rhizosphere and in in vitro culture media. The gac mutants' relative fitness ( $r$ ) was calculated based on the deviation from the initial 1:1 genotype ratio (dashed line) after direct competition in different environments. Fitness values above the dashed line indicate a higher competitive advantage of gac mutants relative to their ancestral genotypes without gac mutations (Table S2), whereas values below the dashed line denote for decreased competitive ability of evolved gac mutants. In all panels, green and beige backgrounds denote competition assays conducted in the rhizosphere and in standard culture media, respectively. All boxplots show median (centre line), interquartile range (25-75\%) and whiskers that extended 1.5 times the interquartile range overlaid with a scatter plot showing independent replicates $(n=$ 3). Different small letters above the boxplots represent significant differences in relative fitness ( $r$ ) between growth conditions for each mutant (one-way ANOVA, Tukey's HSD test, $\alpha=0.05)$. Data for all panels are provided in the Source Data file.

experimental conditions due to production of phytotoxic compounds $^{20}$ (Fig. 1). Crucially, this interaction rapidly evolved during the experiment as bacterial mutualists that had positive effects on the plant growth and relatively higher competitive advantage in the rhizosphere, emerged and swept through replicate bacterial populations.

After the initial bacterial diversification in the rhizosphere, changes in bacterial genotype frequencies could have been driven by bacterial competitive differences. In this case, mutualism could have risen as a simple by-product of bacterial adaptation where competitive superiority was coupled with plant-growth promotion. In support, we found that both mutualists showed reduced secretion of extracellular proteolytic enzymes (Fig. S3A), which was positively correlated with improved plant performance (Fig. S6E). As many metabolites produced by Pseudomonas spp. are costly to produce ${ }^{20}$, such change could have improved the growth of mutualistic bacteria, which was clearly the case with 'Mutualist 1 ' phenotypes. Interestingly, 'Mutualist 1' ability to grow on model root exudates was also positively correlated with MYB72 gene induction, which was associated with a positive effect on plant growth. As a result, increased MYB72 induction could have created a positive feedback loop between plant growth-promotion and 'Mutualist 1' growth on plant root exudates. While evolved 'Mutualist 2' phenotypes also showed lowered proteolytic activity, they did not exert improved growth on tested root exudates. Instead, 'Mutualist 2' phenotypes showed relatively greater increase in their tolerance to the plant-derived antimicrobial scopoletin. Crucially, scopoletin tolerance was also positively coupled with MYB72 gene induction, which is known to be important for scopoletin production and secretion by $A$. thaliana ${ }^{22}$. As a result, plant growth-promotion via MYB72 induction likely improved 'Mutualist 2' competitiveness by leading to increased scopoletin production, which was relatively more harmful to other bacterial phenotypes. The importance of plant selection in driving changes in genotype frequencies was further demonstrated by direct competition assays, where the fitness benefits of mutualists were clearest when measured in the presence of plants. Together, these findings suggest that bacterial mutualism was driven by evolution of reduced phytotoxicity and increased MYB72 induction, which increased both plant growth and mutualists' competitive ability in the plant rhizosphere. Increased MYB72 induction thus likely favoured both types of mutualists, potentially explaining their coexistence within certain plant selection lines (2 and 4).

At the genetic level, evolution of mutualism could be achieved with only a single or a few successive mutations involving mainly global regulators ${ }^{30}$. This result shows an interesting parallel with recent work demonstrating that the loss of a few virulence traits can turn a pathogen into a beneficial symbiont ${ }^{7}$. Evolution of mutualism was also linked with clear phenotypic and genotypic bacterial diversification, which has previously been observed in aquatic $^{43}$ and soil ${ }^{44}$ microcosms in response to spatial heterogeneity. Here we show that such bacterial diversification can also be enforced by plant selection as evidenced by direct competition assays where fitness benefit observed in the rhizosphere was reduced or undetectable in lab media in vitro. Parallel mutations in both gacS and gacA genes suggests that these genes played an essential role in regulating both bacterial competition and interaction with the plant. For example, it is well established that this two-component system regulates the production of phytotoxic 
compounds, such as exoprotease, 2,4-DAPG, hydrogen cyanide and biosurfactants $20,45,46$. As a result, mutations in gacS and gacA genes likely explain observed pleiotropic effects between antagonistic activity ${ }^{29-31}$ and plant performance. These mutations could also have a positive effect on bacterial competitive ability via reduced metabolic costs ${ }^{47}$, and gacA mutations have been shown to affect $15 \%$ of annotated genes in P. aeruginosa M18 including genes involved in the motility, secretion systems and assimilation and metabolism of phosphorus, sulphur, and nitrogen ${ }^{48}$. Even though the role of gac mutations is not known in the case of plant MYB72 induction, gacA has been shown to be important for the full virulence of the plant pathogen Pseudomonas syringae ${ }^{49}$. In this regard, our results are in line with previous studies demonstrating that gacS and gacA mutations selected for less antagonistic (or virulent) $P$. protegens CHA0 genotypes, similar to pathogenic Pseudomonas species. While more research on the underlying molecular mechanisms is required, our findings suggest that the GacS/GacA two-component system could be an important pleiotropic switch for enabling evolution of mutualistic interaction with plants.

Interestingly, we observed a contrasting evolutionary outcome in one of the five selection lines where 'Stress-sensitive' genotypes were able to become dominant alongside with 'Ancestral-like' genotypes potentially due to their enhanced ability to form biofilm and plant root colonization. Interestingly, none of the phenotypes was able to reach fixation in the rhizosphere. One possibility for this is that the experiment was not long enough for the selective sweeps to drive beneficial mutations into fixation, or for the mutualist genotypes to emerge in all selection lines. Alternatively, it is possible that multiple phenotypes were able to coexist due to negative frequency dependent selection or because they occupied different spatial niches as seen in heterogenous soil environments ${ }^{44,50}$. These hypotheses could be studied directly in the future using fluorescent microscopy and tagged strains to observe diversification and genotype fluctuations in the rhizosphere both in space and time.

In summary, our results show that in addition to recruiting beneficial bacteria from multi-species microbial communities $8,9,51$, plants could also change the functioning of its associated microbiota by creating strong selection for de novo evolution of mutualistic bacterial genotypes. Steering bacterial evolution in the rhizosphere could thus offer plants a shortcut to improve their fitness without evolving themselves ${ }^{52-54}$. Future work should focus on validating our findings in more complex microbial communities where bacterial diversification could also be affected by interactions with other microbes. Moreover, it would be interesting to test if mutualism can evolve from initially neutral interaction and if plants can coevolve in response to rhizosphere bacteria. In conclusion, our results call for eco-evolutionary management of plant-microbe interactions in agriculture by demonstrating that plant-associated bacteria can rapidly evolve along the parasitism-mutualism continuum within a few plant growth cycles.

\section{Methods}

Bacterial strain and growth conditions. We used Pseudomonas protegens (formerly Pseudomonas fluorescens $)^{55} \mathrm{CHA} 0$ as a model strain, which was initially isolated from tobacco roots ${ }^{56}$. The strain was chromosomally tagged with GFP and a kanamycin resistance cassette to enable specific tracking of the strain and detection of contaminations ${ }^{19}$. This bacterium has the genetic potential to produce various bioactive metabolites, including the plant hormone indole-3-acetic acid (IAA), antimicrobial compounds and lytic enzymes ${ }^{25}$. Prior to the experiment, bacteria were grown for $48 \mathrm{~h}$ on a King's medium $\mathrm{B}^{57}$ (KB) agar plate supplemented with $50 \mu \mathrm{g} \mathrm{ml}^{-1}$ kanamycin, a single colony was randomly picked and grown for $12 \mathrm{~h}$ in $\mathrm{KB}$ at $28^{\circ} \mathrm{C}$ with agitation. The cell culture was then washed for three times in $10 \mathrm{mM} \mathrm{MgSO}_{4}$ and adjusted to $10^{7}$ cells $\mathrm{ml}^{-1}$ and used as inoculant for all plants. This inoculant was also stored at $-80^{\circ} \mathrm{C}$ as frozen ancestral stock, from which 'Ancestor' isolates were picked in later experiments.
Host plant and growth conditions. We used Arabidopsis thaliana ecotype Col-0 as a model host plant. Surface-sterilized seeds were first sown in Petri dishes with agar-solidified (1.5\% agar (w/v)) modified Hoagland's medium: $\left(\mathrm{KNO}_{3}(3 \mathrm{mM})\right.$, $\mathrm{MgSO}_{4}(0.5 \mathrm{mM}), \mathrm{CaCl}_{2}(1.5 \mathrm{mM}), \mathrm{K}_{2} \mathrm{SO}_{4}(1.5 \mathrm{mM}), \mathrm{NaH}_{2} \mathrm{PO}_{4}(1.5 \mathrm{mM}), \mathrm{H}_{3} \mathrm{BO}_{3}$ $(25 \mu \mathrm{M}), \mathrm{MnSO}_{4}(1 \mu \mathrm{M}), \mathrm{ZnSO}_{4}(0.5 \mu \mathrm{M}),\left(\mathrm{NH}_{4}\right)_{6} \mathrm{Mo}_{7} \mathrm{O}_{24}(0.05 \mu \mathrm{M}), \mathrm{CuSO}_{4}(0.3$ $\mu \mathrm{M})$, MES $(2.5 \mathrm{mM})$ and $50 \mu \mathrm{M} \mathrm{Fe}(\mathrm{III}) \mathrm{EDTA}, \mathrm{pH}=5.8)$ and stratified for 2 days at $4{ }^{\circ} \mathrm{C}$ after Petri dishes were positioned vertically and transferred to a growth chamber $\left(20^{\circ} \mathrm{C}, 10 \mathrm{~h}\right.$ light $/ 14 \mathrm{~h}$ dark, light intensity $\left.100 \mu \mathrm{mol} \mathrm{m}^{-2} \mathrm{~s}^{-1}\right)$. After 2 weeks of incubation, two seedlings were transferred to closed and sterile ECO2 boxes (http://www.eco2box.com/ov80xxl nl.htm) for selection experiment. The ECO2 boxes were filled with $260 \mathrm{~g}$ of dry, carbon-free silver sand that was pre viously washed with MilliQ water to remove dissolvable chemical elements and heated to $550^{\circ} \mathrm{C}$ for $24 \mathrm{~h}$ to remove remaining organic material. Prior to transplantation the sand was amended with $13 \mathrm{ml}$ of modified Hoagland medium.

Design of the selection experiment. The selection experiment was conducted in a gnotobiotic system to remove confounding effects that may emerge as a result of competitive interactions with other microorganisms, and to place the focus on plant-mediated selective pressures. Moreover, we allowed only the bacteria to evolve during the experiment and used new clonal plants at every bacterial transfer We set up five independent plant-bacterium replicate lines, which were grown for six independent plant growth cycles (see Fig. S1 for an overview of the experimental design). The experiment was started by inoculating $10^{6}$ cells of the stock $P$ protegens CHA0 culture (from here on abbreviated as 'ancestor') into the rhizosphere of 2-week-old $A$. thaliana seedlings growing in sterile silver sand within ECO2 boxes (two plants per replicate selection line). Inoculated plants were then grown for 4 weeks $\left(20^{\circ} \mathrm{C}, 10 \mathrm{~h}\right.$ light $/ 14 \mathrm{~h}$ dark, light intensity $\left.100 \mu \mathrm{mol} \mathrm{m}^{-2} \mathrm{~s}^{-1}\right)$ after which the plant growth cycle was terminated and root-associated bacteria were harvested by placing the roots of both plants into a $1.5 \mathrm{ml}$ Eppendorf tubes filled with $1 \mathrm{ml} 10 \mathrm{mM} \mathrm{MgSO}_{4}$ and two glass beads. Rhizosphere bacteria were suspended into the liquid using a TissueLyser II at a frequency of $20 \mathrm{~s}^{-1}$ for $1 \mathrm{~min}$ after which bacterial cell densities were determined using flow cytometry (BD Accuri $^{\text {m }}$ C6 Plus, thresholds for FSC: 2000, SSC: 8000). After this, $10^{6}$ cells were inoculated to the rhizosphere of new A. thaliana plants to initiate the next plant growth cycle. Possible contaminations were checked by plating the suspension on $3 \mathrm{gl}^{-1}$ tryptic soy agar (TSA) plates and it was verified that all colonies carried the GFP marker gene, as observed under UV light.

Bacterial life-history traits measurements. Individual bacterial colonies were isolated from all replicate plant selection lines for life-history measurements at the end of the second, fourth and sixth plant growth cycle by dilution plating the rhizosphere suspension on $3 \mathrm{~g} \mathrm{l}^{-1}$ TSA plates. After incubation at $28^{\circ} \mathrm{C}$ for $24 \mathrm{~h}, 16$ colonies were randomly picked from each replicate selection lines resulting in a total of 240 evolved and 16 ancestral colonies. All these colonies were characterized for a set of key bacterial life-history traits representative of growth, stress resistance and traits linked with plant-microbe interactions.

a. Bacterial growth yield in KB medium

All the bacterial isolates were grown in 96-well plates with $160 \mu \mathrm{l} 1 / 3$ strength liquid $\mathrm{KB}$, at $20^{\circ} \mathrm{C}$ without shaking. Bacterial yield was determined as the maximum optical density at $600 \mathrm{~nm}$ after 3 days of growth using a spectrophotometer (SPECTROstar Nano).

b. Bacterial stress resistance

We measured bacterial resistance to a range of different stresses using various 96-well microplate assays. Abiotic stress resistance was determined by growing bacteria in $160 \mu \mathrm{l}$ of $1 \mathrm{gl}^{-1} \mathrm{TSB}$ containing $0.0025 \% \mathrm{H}_{2} \mathrm{O}_{2}$ (oxidative stress), 15\% polyethylene glycol (PEG)-6000 (water potential stress) or $2 \% \mathrm{NaCl}$ (salt stress). We used resistance to antibiotics commonly produced by rhizosphere microorganisms as indicator of biotic stress resistance. Antibiotic resistance was tested in $160 \mu \mathrm{l}$ of $1 \mathrm{gl}^{-1} \mathrm{TSB}$ supplemented with $1 \mu \mathrm{g} \mathrm{ml}^{-1}$ streptomycin, $1 \mu \mathrm{g} \mathrm{ml}^{-1}$ tetracycline, or $5 \mu \mathrm{g}$ $\mathrm{ml}^{-1}$ penicillin, respectively. Bacterial growth were determined after 3 days of growth at $20^{\circ} \mathrm{C}$ without shaking as optical density at $600 \mathrm{~nm}$.

c. Traits linked with plant-microbe interactions

$P$. protegens $\mathrm{CHA} 0$ harbours several traits that are linked to plant growth including production of antibiotics and plant hormones. To assess these traits, we grew each bacterial colony in 96-well plates containing $160 \mu \mathrm{l}$ of $1 / 3$ strength liquid $\mathrm{KB}$ per well at $20^{\circ} \mathrm{C}$ without shaking for $72 \mathrm{~h}$. Cell-free supernatants were obtained by filter sterilization $(0.22 \mu \mathrm{m})$ using Multiscreen HTS 96-well filtration plates $(1000 \times g$, $30 \mathrm{~min})$, which were used to measure the production of the plant hormone auxin (Indole-3-acetic acid (IAA)), iron-chelating siderophores and proteolytic activity. Furthermore, we also measured antifungal and antibacterial activity of all colonies.

IAA detection. The production of the plant hormone auxin was determined with a colorimetric test ${ }^{58}$. Briefly, $30 \mu \mathrm{l} P$. protegens $\mathrm{CHA} 0$ cell-free filtrate was incubated with $30 \mu \mathrm{R} 1$ reagent $\left(12 \mathrm{gl}^{-1} \mathrm{FeCl}_{3}, 7.9 \mathrm{M} \mathrm{H}_{2} \mathrm{SO}_{4}\right)$ for $12 \mathrm{~h}$ in the dark and optical density read at $530 \mathrm{~nm}$ of the colorimetric complex was used as a measurement of IAA concentration. 
Siderophore activity. Iron-chelating ability was measured as a proxy for siderophore production ${ }^{59}$. To this end, $100 \mu \mathrm{l}$ of $P$. protegens $\mathrm{CHA} 0$ cell-free filtrate was mixed with $100 \mu \mathrm{l}$ of modified CAS solution (with $0.15 \mathrm{mM} \mathrm{FeCl}_{3}$ ) and optical density read at $630 \mathrm{~nm}$ after $3 \mathrm{~h}$ of incubation was used as a proxy of siderophore production. The iron-chelating ability was calculated based on the standard curve based on modified CAS assay solution with a range of iron concentration $\left(0,0.0015,0.003,0.006,0.009,0.012,0.015 \mathrm{mM} \mathrm{FeCl}_{3}\right)$.

Proteolytic activity. The proteolytic activity assay we used was adapted from Smeltzer et al. ${ }^{60}$. Briefly, $15 \mu \mathrm{l}$ of $P$. protegens $\mathrm{CHA0}$ cell-free filtrate was incubated with $25 \mu \mathrm{l}$ of azocasein $(2 \% \mathrm{w} / \mathrm{v}$ in $50 \mathrm{mM}$ Tris- $\mathrm{HCl} \mathrm{pH} \mathrm{8.0)} \mathrm{at}$ $40{ }^{\circ} \mathrm{C}$ for $24 \mathrm{~h}$. One hundred and twenty-five of $10 \% \mathrm{w} / \mathrm{v}$ cold trichloroacetic acid (TCA) was added to precipitate superfluous azocasein, and then $100 \mu \mathrm{l}$ supernatant was neutralized with $100 \mu \mathrm{l}$ of $1 \mathrm{M} \mathrm{NaOH}$ after centrifugation at $5000 \mathrm{~g}$ for $30 \mathrm{~min}$. Optical density read at $440 \mathrm{~nm}$ was used as a proxy of exoprotease activity.

Tryptophan side chain oxidase (TSO) activity. TSO activity, an indicator of quorum sensing activity in $P$. protegens CHA0, was measured based on an modified established colorimetric assay ${ }^{61}$ : Three-day-old bacterial cultures grown in $1 / 3$ strength liquid $\mathrm{KB}$ were mixed at a 1:1 ratio with a reagent solution ( $5 \mathrm{gl}^{-1} \mathrm{SDS}, 37.6 \mathrm{gl}^{-1}$ glycine $2.04 \mathrm{l}^{-1} \mathrm{~g}$ tryptophan, $\mathrm{pH}$ 3.0) and TSO activity was measured as optical density at $600 \mathrm{~nm}$ after overnight incubation.

Biofilm formation. We quantified bacterial biofilm formation using a standard protocol ${ }^{62}$. Briefly, bacteria were grown at $20^{\circ} \mathrm{C}$ for $72 \mathrm{~h}$ in $160 \mu \mathrm{l} 1 \mathrm{gl}^{-1} \mathrm{TSB}$ in a 96-well microtiter plate with TSP lid (TSP, NUNC, Roskilde, Denmark). Planktonic cells were removed by immersing the lid with pegs three times in phosphate-buffered saline solution (PBS). Subsequently, the biofilm on the pegs was stained for $20 \mathrm{~min}$ in $160 \mu \mathrm{l} \%$ crystal violet solution. Pegs were washed five times in PBS after which the crystal violet was extracted for $20 \mathrm{~min}$ from the biofilm in a new 96-well microtiter plate containing $200 \mu \mathrm{l}$ $96 \%$ ethanol per well. Biofilm formation was defined as the optical density at $590 \mathrm{~nm}$ of the ethanol extracted crystal violet ${ }^{63}$.

Inhibition of other microorganisms. Antimicrobial activity was defined as the relative growth of the target organism in $P$. protegens supernatant compared to the control treatment. Antifungal activity of the cell-free supernatant was assessed against the ascomycete Verticillium dahliae. The fungus was grown on potato dextrose agar at $28^{\circ} \mathrm{C}$ for 4 days, after which plugs of fungal mycelium were incubated in potato dextrose broth medium at $28^{\circ} \mathrm{C}$ and gentle shaking for 5 days. Fungal spores were collected by filtering out the mycelium from this culture over glass wool. Subsequently, spores were washed and resuspended in water and the $\mathrm{OD}_{595}$ of the suspension was adjusted to 1 . Five microlitres of this spore suspension was then inoculated with $15 \mu \mathrm{l}$. protegens $\mathrm{CHA} 0$ cellfree filtrate and incubated in $160 \mu \mathrm{l} \mathrm{of} 1 \mathrm{gl}^{-1} \mathrm{PDB}$ medium for 2 days at $20^{\circ} \mathrm{C}$ in 96-well plates. Fungal growth was measured as optical density at $595 \mathrm{~nm}$ after 2 days of growth and contrasted with the growth in the control treatment (PDB medium without $P$. protegens supernatant). Antibacterial activity was determined using the plant pathogen Ralstonia solanacearum as a target organism. R. solanacearum was grown in $160 \mu \mathrm{l}$ of $1 \mathrm{gl}^{-1}$ TSB medium supplemented with $15 \mu \mathrm{l}$ of $P$. protegens CHA0 cell-free filtrate or $15 \mu \mathrm{l}$ of $1 / 3$ strength liquid $\mathrm{KB}$ as a control for 2 days at $20^{\circ} \mathrm{C}$. $R$. solanacearum growth was measured as optical density at $600 \mathrm{~nm}$.

Determining changes in P. protegens CHAO interactions with A. thaliana after the selection experiment. Based on the life-history trait measurements, five distinct bacterial phenotypes were identified using $K$-means clustering analysis (Fig. S2). In order to assess whether phenotypic changes reflected shifts in the strength and type of plant-bacterium interaction, we chose five isolates from each bacterial phenotype group representing each replicate selection line and five ancestral isolates for further measurements (a total of 30 isolates, Table S2).

Effects of ancestor and evolved bacteria on plant performance. For each isolate we measured root colonizing ability and impact on plant performance. All 30 bacterial isolates were incubated overnight in $1 / 3 \mathrm{~KB}$ strength liquid at $20^{\circ} \mathrm{C}$. The culture was centrifuged twice for $5 \mathrm{~min}$ at $5000 \times g$ and the pellet was washed and finally resuspended in $10 \mathrm{mM} \mathrm{MgSO}_{4}$. The resulting suspension was adjusted to an $\mathrm{OD}_{600}$ of 0.01 for each strain ${ }^{64}$. Ten microlitres of the bacterial suspension (or $10 \mathrm{mM}$ $\mathrm{MgSO}_{4}$ as a control) was applied to the roots of three 10-day old sterile Arabidopsis thaliana Col-0 seedlings (excluding 2 days of stratification at $4{ }^{\circ} \mathrm{C}$ ) grown on vertically positioned Petri dishes with agar-solidified $(1.5 \%$ agar $(\mathrm{w} / \mathrm{v}))$ modified Hoagland's medium ( $n=3$ biological plant replicates, each containing 3 seedlings). Plants were grown for 14 days before harvesting. Plants were photographed before and 14 days after bacterial inoculation.

Bacterial effects on plant health were quantified as leaf 'greenness' as the presence of ancestral strain was observed to lead to bleaching and loss of chlorophyll in A. thaliana leaves. The 'greenness' was quantified from photographs by measuring the number of green pixels. To this end, photographs were first transformed in batch using Adobe Photoshop 2021 by sequentially selecting only green areas followed by thresholding balancing green tissue over background noise (Level 80). This resulted in black-and-white images for further analysis, and the mean number of white pixels per fixed-sized region-of-interest of the aboveground tissue was subsequently determined as 'greenness' using ImageJ (version 1.50i). The numbers of lateral roots and the primary root length were also measured using ImageJ. The root morphology data measured at the end of the experiment was normalized with the data collected at the time of inoculation for each individual seedling.

To determine shoot biomass, the rosette of each plant was separated from the root system with a razor blade and weighted. The roots were placed into a preweighted $1.5 \mathrm{ml}$ Eppendorf tubes to quantify the root biomass. To determine the bacterial abundance per plant, these tubes were subsequently filled with $1 \mathrm{ml}$ $10 \mathrm{mM} \mathrm{MgSO} 4$ buffer solution and two glass beads. The rhizosphere bacteria were suspended into the buffer solution using a TissueLyser II at a frequency of $20 \mathrm{~s}^{-1}$ for $1 \mathrm{~min}$ after which bacterial densities were determined using flow cytometry (BD Accurit $^{\text {in }}$ C6 Plus, thresholds for FSC: 2000, SSC: 8000). Shoot biomass, root biomass, root length and number of lateral roots were used in a principal component analysis (PCA) to calculate an overall impact of the bacteria on plant performance (Fig. 2e). The first principal component (PC1) explained $79.9 \%$ of the variation and was normalized against the control treatment to be used as a proxy of 'Plant performance' in which positive values reflect plant growth promotion and negative values plant growth inhibition.

Root derived carbon source utilization. To measure changes in bacterial growth on potential root derived carbon sources, we measured the growth of all 256 isolates using modified Ornston and Stanier (OS) minimal medium ${ }^{65}$ supplemented with single carbon sources at a final concentration of $0.5 \mathrm{gl}^{-1}$ in 96 -well plates containing $160 \mu \mathrm{l}$ carbon supplemented OS medium per well. The following carbon sources were selected based on their relatively high abundance in Arabidopsis root exudates ${ }^{21}$ : alanine, arabinose, butyrolactam, fructose, galactose, glucose, glycerol, glycine, lactic acid, putrescine, serine, succinic acid, threonine and valine. Bacterial growth was determined by measuring optical density at $600 \mathrm{~nm}$ after 3 days incubation at $20^{\circ} \mathrm{C}$.

GUS histochemical staining assay and bacterial growth under scopoletin stress. To investigate effects of the ancestor and evolved strains of $P$. protegens $\mathrm{CHA} 0$ on expression of MYB72, we applied a GUS histochemical staining assay to the 30 selected isolates (Table S2). MYB72 is a transcription factor involved in production of the coumarin scopoletin in Arabidopsis roots and specific rhizobacteria can upregulate expression of MYB72 in the roots ${ }^{66}$. Scopoletin is an ironmobilizing phenolic compound with selective antimicrobial activity 22 . Seedlings of the $A$. thaliana $M Y B 72_{\text {pro: }}$ GFP-GUS ${ }^{24}$ reporter line were prepared as described above. Seven-day-old seedlings were inoculated directly below the hypocotyls with $10 \mu \mathrm{l}$ of a bacterial suspension $\left(\mathrm{OD}_{660}=0.1\right)^{24}$. At 2 days after inoculation, the roots were separated from the shoots and washed in MilliQ water (Milliport Corp., Bedford, MA) to remove all the adhered bacteria. GUS staining of the roots was performed in 12-well microtiter plates where each well contained roots of 5-6 seedlings and $1 \mathrm{ml}$ of freshly prepared GUS substrate solution $(50 \mathrm{mM}$ sodium phosphate with a $\mathrm{pH}$ at $7,10 \mathrm{mM}$ EDTA, $0.5 \mathrm{mM} \mathrm{K} 4[\mathrm{Fe}(\mathrm{CN}) 6], 0.5 \mathrm{mM} \mathrm{K} 3[\mathrm{Fe}$ (CN)6], $0.5 \mathrm{mM}$ X-Gluc, and $0.01 \%$ Silwet L-77) ${ }^{67}$. Plates were incubated in the dark at room temperature for $16 \mathrm{~h}$. The roots were fixed overnight in $1 \mathrm{ml}$ ethanol: acetic acid $(3: 1 \mathrm{v} / \mathrm{v})$ solution at $4{ }^{\circ} \mathrm{C}$ and transferred to $75 \%$ ethanol. Then the pictures of each microtiter plates were taken, and GUS activity was quantified by counting the number of blue pixels in each well of the microtiter plates using image analysis in ImageJ (version 1.52t). To assess the effects of scopoletin on ancestral and evolved $P$. protegens $\mathrm{CHA} 0$ isolates, we applied a sensitivity assay to the 30 selected isolates (Table S2). In brief, growth of bacterial isolates was measured in $1 \mathrm{gl}^{-1}$ TSB medium $(160 \mu \mathrm{l})$ supplemented with scopoletin at final concentrations of $0 \mu \mathrm{M}$ (control), $500 \mu \mathrm{M}, 1000 \mu \mathrm{M}$, and $2 \mathrm{mM}$ using optical density at $600 \mathrm{~nm}$ after $72 \mathrm{~h}$ incubation at $20^{\circ} \mathrm{C}$ without shaking in 96 -well microtiter plates. Maximal effect (Emax) of scopoletin was calculated via R package 'GRmetrics' 68 as an indication of scopoletin tolerance.

Whole-genome sequencing. All 30 isolated phenotypes were whole genome sequenced to identify possible mutations and affected genes. To this end, isolates were cultured overnight at $28^{\circ} \mathrm{C}$ in $1 / 3$ strength liquid $\mathrm{KB}$. Chromosomal DNA was isolated from each culture using the GenElute ${ }^{\mathrm{me}}$ Bacterial Genomic DNA Kit Protocol (NA2100). DNA samples were sheared on a Covaris E-220 Focused-ultrasonicator and sheared DNA was then used to prepare Illumina sequencing libraries with the NEBNext ${ }^{\oplus}$ Ultra ${ }^{\mathrm{m}}$ DNA Library Prep Kit (New England Biolabs. France) and the NEBNext ${ }^{\circledR}$ Multiplex Oligos for Illumina ${ }^{\circledR}$ (96 Index Primers). The final libraries were sequenced in multiplex on the NextSeq 500 platform $(2 \times 75$ bp paired-end $)$ by the Utrecht Sequencing Facility (http://www.useq.nl) yielding between 1.0 and 6.4 million reads per sample equivalent to $\sim 10-70$-fold coverage (based on comparison with the original 6.8 Mbp reference genome NCBI GenBank: CP003190.1).

Variant calling analysis. We first constructed an updated reference genome of $P$. protegens CHA0, carrying the GFP marker gene on its chromosome, from the ancestral strain using the A5 pipeline with default parameters ${ }^{69}$. The input dataset 
for this sample consisted of 3,1M reads and totals an approximate 34-fold coverage. The size of the updated reference genome is $6.8 \mathrm{Mbp}$, with a G + C content of $63.4 \%$, and it comprises 80 scaffolds, with a $N_{50}$ value of $343 \mathrm{kbp}$. We subsequently used PROKKA ${ }^{70}$ (version 1.12; https://github.com/tseemann/prokka) for full annotation of the updated reference genome, and this resulted in the identification of 6147 genes. The updated genome is deposited in NCBI GenBank with following reference: RCSR00000000.1.

Having established the ancestral genome sequence, we subsequently used Snippy (version 3.2-dev; https://github.com/tseemann/snippy) to identify and functionally annotate single-nucleotide polymorphisms and small insertions and deletions (indels) for each individual strain. In addition, we investigated the breadth of coverage for each gene per sample with BedTools ${ }^{71}$ to identify genes with large insertions or deletions. An overview of the polymorphisms is shown in Supplementary Table S3. Raw sequencing data for this study are deposited at the NCBI database under BioProject PRJNA473919.

Relative competitive fitness of gac mutants measured in vivo and in vitro. The relative competitive fitness of selected $g a c$ mutants was measured in direct competition with their direct ancestors both in vivo in the rhizosphere of A. thaliana and in vitro in different standard culture media. Relative fitness was measured as deviation from initial 1:1 ratio of bacterial clone pairs based on PCR-based highresolution melting profile (RQ-HRM) analysis. Three pairs of isolates were selected: (A) evolved gacA ID 242 (genotype oafA ${ }^{\mathrm{Y} 335 \mathrm{X}}$. RS17350 $177 \mathrm{~A} . \mathrm{fSX} 14 \cdot$ gacA $^{\mathrm{D} 49 \mathrm{Y}}$ ) and its direct ancestral genotype 133 (genotype oafA ${ }^{\mathrm{Y} 335 \mathrm{X}} \cdot$ RS17350 A77A.fsX14) from evolutionary line 1 ; (B) evolved gacA ID 220 (genotype galE $^{\mathrm{V} 32 \mathrm{M}} \cdot \operatorname{accC}^{\mathrm{E} 413 \mathrm{~K}}$. $g a c A^{\mathrm{D} 54 \mathrm{Y}}$ ) and its direct ancestral genotype 28 (genotype galE $^{\mathrm{V} 32 \mathrm{M}} \cdot a c c C^{\mathrm{E} 413 \mathrm{~K}}$ ) from line 2; (c) evolved gacS ID 222 (genotype oafA $\mathrm{K}^{\mathrm{3} 38 \mathrm{~S} . \mathrm{IsX} 18} \cdot \mathrm{gacS}^{\mathrm{G} 27 \mathrm{D}}$ ) and its direct ancestral genotype 66 (genotype oaf $A^{\mathrm{K} 3385 . \text {.fs } 18}$ ) from line 3 . Bacterial isolates were first grown overnight in $\mathrm{KB}$ medium at $28^{\circ} \mathrm{C}$, centrifuged at $5000 \mathrm{~g}$ for $10 \mathrm{~min}$ and the pellet resuspended in $10 \mathrm{mM} \mathrm{MgSO}_{4}$. This washing procedure was repeated twice. The resulting bacterial suspensions were diluted to $\mathrm{OD}_{600}=0.05$. The initial inoculum for the competition assays was then generated by mixing equal volumes of evolved and ancestral competitors in a ratio of 1:1

Measuring competitive fitness in A. thaliana rhizosphere. This assay was performed on the roots of 10-day old $A$. thaliana seedlings grown on full strength Hoagland agar plates, which were prepared as described earlier. Twenty microlitres of the initial inoculum, containing a total of $10^{6}$ bacterial cells, was inoculated on to the root-shoot junction of each seedling. After 14 days of growth, bacterial populations were isolated from the roots and stored at $-80{ }^{\circ} \mathrm{C}$ in $42.5 \%$ glycerol for relative abundance measurements.

Measuring competitive fitness in culture media. Competition assays were also performed in three commonly used nutrient-rich growth media: KB, LB and TSB. $\mathrm{KB}$ contained $20 \mathrm{~g}$ proteose peptone, $1.5 \mathrm{~g} \mathrm{MgSO}_{4} .7 \mathrm{H}_{2} \mathrm{O}, 1.2 \mathrm{~g} \mathrm{KH}_{2} \mathrm{PO}_{4}$ and $10 \mathrm{~g}$ glycerol per litre and the $\mathrm{pH}$ was adjusted to $7.3 \pm 0.2$. TSB contained $30 \mathrm{~g}$ tryptic soy broth per litre and $\mathrm{pH}$ was adjusted to $7.3 \pm 0.2$. LB contained $10 \mathrm{~g}$ peptone, $5 \mathrm{~g}$ yeast extract and $5 \mathrm{~g} \mathrm{NaCl}$ per litre. Twenty microlitres inoculum of competing strains, containing about $10^{6}$ bacterial cells, were added into wells containing $140 \mu \mathrm{l}$ fresh medium in a 96-well plate. The microplates were incubated at $28^{\circ} \mathrm{C}$ without shaking for 48 after $80 \mu \mathrm{l}$ sample was harvested and stored at $-80^{\circ} \mathrm{C}$ in $42.5 \%$ glycerol from each well for relative abundance measurements.

RQ-HRM assay for quantifying changes in genotype frequencies after competition. We used a high-resolution melting (HRM) curve profile assay with integrated LunaProbes to quantify the ratio of mutant to wild-type genotypes ${ }^{72-74}$. The probes and primers used in this study are listed in Table S4. Primers were designed using Primer3. Probes were designed with the single-nucleotide polymorphism (SNP) located in the middle of the sequence, and the $3^{\prime}$ end was blocked by carbon spacer $\mathrm{C} 3$. The primer asymmetry was set to 2:1 (excess primer: limiting primer) in all cases. Pre-PCR was performed in a $10-\mu \mathrm{l}$ reaction system, with $0.25 \mu \mathrm{M}$ excess primer, $0.125 \mu \mathrm{M}$ limiting primer, $0.25 \mu \mathrm{M}$ probe, $0.5 \mu \mathrm{l}$ bacterial sample culture (100-fold diluted saved sample, $\mathrm{OD}_{600}$ is about 0.01 ), $1 \times$ LightScanner Master Mix (BioFire Defense). DMSO with the final concentration 5\% was supplemented in all reactions to ensure the targeted melting domains are within the detection limit of the LightScanner (Idaho Technology Inc.). Finally, MQ water was used to supplement up to $10 \mu \mathrm{l}$. A 96-well black microtiter plate with white wells was used to minimize background fluorescence. Before amplification, $25 \mu \mathrm{l}$ mineral oil was loaded in each well to prevent evaporation, and the plate was covered with a foil seal to prevent the degradation of fluorescent molecules. Amplification was initiated by a holding at $95^{\circ} \mathrm{C}$ for $3 \mathrm{~min}$, followed by 55 cycles of denaturation at $95^{\circ} \mathrm{C}$ for $30 \mathrm{~s}$, annealing at $60^{\circ} \mathrm{C}$ for $30 \mathrm{~s}$ and extension at $72^{\circ} \mathrm{C}$ for $30 \mathrm{~s}$ and then kept at $72{ }^{\circ} \mathrm{C}$ for $10 \mathrm{~min}$. After amplification, samples were heated in a ThermalCycler (Bio-Rad) shortly to $95^{\circ} \mathrm{C}$ for $30 \mathrm{~s}$ to denature all double-stranded structures followed by a rapid cooling to $25^{\circ} \mathrm{C}$ for $30 \mathrm{~s}$ to facilitate successful hybridization between probes and the target strands. The plate was then transferred to a LightScanner (Idaho Technology Inc.). Melting profiles of each well were collected by monitoring the continuous loss of fluorescence with a steady increase of the temperature from 35 to $97^{\circ} \mathrm{C}$ with a ramp rate of $0.1{ }^{\circ} \mathrm{C} / \mathrm{s}$. The relative quantification was based on the negative first derivative plots using software MATLAB.
The areas of probe-target duplexes melting peaks were auto-calculated by 'AutoFit Peaks I Residuals' function in software PeakFit (SeaSolve Software Inc.). The mutant frequency $X$ was calculated using the formula shown below:

$$
X=\frac{\text { Area }_{\text {mutant }}}{\text { Area }_{\text {mutant }}+\text { Area }_{\mathrm{WT}}}
$$

To validate the RQ-HRM method, standard curves were generated by measuring mixed samples with known proportions of mutant templates: $0,10,20$, $30,40,50,60,70,80,90$ and $100 \%$. Measurements for each sample were done in triplicate. Linear regression formula of each mutant between actual frequencies and measured frequencies are shown in Fig. S7. The high $R^{2}$ values, and nearly equal to 1 slope values of these equations, confirmed that the RQ-HRM method can accurately detect mutants' frequency in a mixed population.

The relative fitness of the evolved strains was calculated according to previous studies using the following equation ${ }^{75,76}$ :

$$
\text { relative fitness }(r)=\frac{X_{1}\left(1-X_{0}\right)}{X_{0}\left(1-X_{1}\right)}
$$

where $X_{0}$ is the initial mutant frequency; $\left(1-X_{0}\right)$ the initial ancestor frequency; $X_{1}$ the final mutant frequency; and $\left(1-X_{1}\right)$ is the final ancestor frequency.

Reporting summary. Further information on research design is available in the Nature Research Reporting Summary linked to this article.

\section{Data availability}

The Pseudomonas protegens CHA0-GFP reference strain genome sequence, determined for this study, is deposited on GenBank with accession RCSR00000000.1. Raw sequencing data used in this study are deposited at the NCBI database under BioProject PRINA473919. Raw data of $P$. protegens CHA0 phenotypic traits are described in Supplementary Data 1-3, which are also deposited at Mendeley Data: https:/doi.org/ $10.17632 / 3 \mathrm{~g} 6 \mathrm{db} 3 \mathrm{pj} 6 \mathrm{~b} .2$. Source data are provided with this paper.

\section{Code availability}

$\mathrm{R}$ code is deposited on GitHub (https://github.com/erqinli/plant-rhizosphere-mutualist; https://doi.org/10.5281/zenodo.4750789). Source data are provided with this paper.

Received: 7 December 2020; Accepted: 24 May 2021; Published online: 22 June 2021

\section{References}

1. Berendsen, R. L., Pieterse, C. M. J. \& Bakker, P. A. H. M. The rhizosphere microbiome and plant health. Trends Plant Sci. 17, 478-486 (2012).

2. Philippot, L., Raaijmakers, J. M., Lemanceau, P. \& van der Putten, W. H. Going back to the roots: the microbial ecology of the rhizosphere. Nat. Rev. Microbiol. 11, 789-799 (2013)

3. Dethlefsen, L., McFall-Ngai, M. \& Relman, D. A. An ecological and evolutionary perspective on human-microbe mutualism and disease. Nature 449, 811-818 (2007).

4. Brownlie, J. C. \& Johnson, K. N. Symbiont-mediated protection in insect hosts. Trends Microbiol. 17, 348-354 (2009).

5. Kiers, E. T. \& Denison, R. F. Sanctions, cooperation, and the stability of plant-rhizosphere mutualisms. Annu. Rev. Ecol. Evol. Syst. 39, 215-236 (2008).

6. King, K. C. et al. Rapid evolution of microbe-mediated protection against pathogens in a worm host. ISME J. 10, 1915-1924 (2016).

7. Tso, G. H. W. et al. Experimental evolution of a fungal pathogen into a gut symbiont. Science 362, 589-595 (2018).

8. Berendsen, R. L. et al. Disease-induced assemblage of a plant-beneficial bacterial consortium. ISME J. 12, 1496-1507 (2018).

9. Sasse, J., Martinoia, E. \& Northen, T. Feed your friends: do plant exudates shape the root microbiome? Trends Plant Sci. 23, 25-41 (2018).

10. Bakker, P. A. H. M. et al. The soil-borne identity and microbiome-assisted agriculture: looking back to the future. Mol. Plant 13, 1394-1401 (2020).

11. Johnson, N. C., Graham, J. H. \& Smith, F. A. Functioning of mycorrhizal associations along the mutualism-parasitism continuum. N. Phytol. 135, 575-586 (1997).

12. Kogel, K. H., Franken, P. \& Hückelhoven, R. Endophyte or parasite-what decides? Curr. Opin. Plant Biol. 9, 358-363 (2006).

13. Cosme, M., Fernández, I., Van der Heijden, M. G. A. \& Pieterse, C. M. J. Nonmycorrhizal plants: the exceptions that prove the rule. Trends Plant Sci. 23, 577-587 (2018).

14. Wein, T. et al. Currency, exchange, and inheritance in the evolution of symbiosis. Trends Microbiol. 27, 836-849 (2019).

15. Chomicki, G., Kiers, E. T. \& Renner, S. S. The evolution of mutualistic dependence. Annu. Rev. Ecol. Evol. Syst. 51, 409-432 (2020). 
16. Stringlis, I. A., Zhang, H., Pieterse, C. M. J., Bolton, M. D. \& De Jonge, R. Microbial small molecules-weapons of plant subversion. Nat. Prod. Rep. 35 , 410-433 (2018).

17. Kramer, J., Özkaya, Ö. \& Kümmerli, R. Bacterial siderophores in community and host interactions. Nat. Rev. Microbiol. 18, 152-163 (2020).

18. Kawecki, T. J. et al. Experimental evolution. Trends Ecol. Evol. 27, 547-560 (2012).

19. Jousset, A., Lara, E., Wall, L. G. \& Valverde, C. Secondary metabolites help biocontrol strain Pseudomonas fluorescens CHA0 to escape protozoan grazing. Appl. Environ. Microbiol. 72, 7083-7090 (2006).

20. Brazelton, J. N., Pfeufer, E. E., Sweat, T. A., Gardener, B. B. M. \& Coenen, C. 2,4-Diacetylphloroglucinol alters plant root development. Mol. Plant Microbe Interact. 21, 1349-1358 (2008).

21. Chaparro, J. M. et al. Root exudation of phytochemicals in Arabidopsis follows specific patterns that are developmentally programmed and correlate with soil microbial functions. PLoS ONE 8, e55731 (2013).

22. Stringlis, I. A. et al. MYB72-dependent coumarin exudation shapes root microbiome assembly to promote plant health. Proc. Natl Acad. Sci. USA 115, E5213-E5222 (2018).

23. Voges, M. J. E. E. E., Bai, Y., Schulze-Lefert, P. \& Sattely, E. S. Plant-derived coumarins shape the composition of an Arabidopsis synthetic root microbiome. Proc. Natl Acad. Sci. USA 116, 12558-12565 (2019).

24. Zamioudis, C. et al. Rhizobacterial volatiles and photosynthesis-related signals coordinate MYB72 expression in Arabidopsis roots during onset of induced systemic resistance and iron-deficiency responses. Plant J. 84, 309-322 (2015).

25. Jousset, A. et al. Full-genome sequence of the plant growth-promoting bacterium Pseudomonas protegens CHA0. Genome Announc 2, e00322-14 (2014).

26. Barrick, J. E. \& Lenski, R. E. Genome dynamics during experimental evolution. Nat. Rev. Genet. 14, 827-839 (2013).

27. Yang, L. et al. Evolutionary dynamics of bacteria in a human host environment. Proc. Natl Acad. Sci. USA 108, 7481-7486 (2011)

28. Haas, D. \& Défago, G. Biological control of soil-borne pathogens by fluorescent pseudomonads. Nat. Rev. Microbiol. 3, 307-319 (2005).

29. Reyrat, J. M., David, M., Batut, J. \& Boistard, P. FixL of Rhizobium meliloti enhances the transcriptional activity of a mutant FixJD54N protein by phosphorylation of an alternate residue. J. Bacteriol. 176, 1969-1976 (1994).

30. Laville, J. et al. Global control in Pseudomonas fluorescens mediating antibiotic synthesis and suppression of black root rot of tobacco. Proc. Natl Acad. Sci. USA 89, 1562-1566 (1992)

31. Bull, C. T. et al. Characterization of spontaneous gacS and gacA regulatory mutants of Pseudomonas fluorescens biocontrol strain CHA0. Antonie Van. Leeuwenhoek 79, 327-336 (2001).

32. Zhang, R. et al. Structure of a bacterial quorum-sensing transcription factor complexed with pheromone and DNA. Nature 417, 971-974 (2002).

33. Song, C. et al. The Rsm regulon of plant growth-promoting Pseudomonas fluorescens SS101: role of small RNAs in regulation of lipopeptide biosynthesis. Microb. Biotechnol. 8, 296-310 (2015).

34. Battesti, A., Majdalani, N. \& Gottesman, S. The RpoS-mediated general stress response in Escherichia coli. Annu. Rev. Microbiol. 65, 189-213 (2011).

35. Stockwell, V. O. \& Loper, J. E. The sigma factor RpoS is required for stress tolerance and environmental fitness of Pseudomonas fluorescens Pf-5. Microbiology 151, 3001-3009 (2005).

36. Heeb, S., Valverde, C. \& Haas, D. Role of the stress sigma factor RpoS in GacA/ RsmA-controlled secondary metabolism and resistance to oxidative stress in Pseudomonas fluorescens CHA0. FEMS Microbiol. Lett. 243, 251-258 (2005)

37. Whiteley, M. et al. Gene expression in Pseudomonas aeruginosa biofilms. Nature 413, 860-864 (2001).

38. Ramey, B. E., Koutsoudis, M., Bodman, S. B. V. \& Fuqua, C. Biofilm formation in plant-microbe associations. Curr. Opin. Microbiol. 7, 602-609 (2004).

39. Fukami, T., Beaumont, H. J. E., Zhang, X. X. \& Rainey, P. B. Immigration history controls diversification in experimental adaptive radiation. Nature 446, 436-439 (2007).

40. Fukami, T. Historical contingency in community assembly: integrating niches, species pools, and priority effects. Annu. Rev. Ecol. Evol. Syst. 46, 1-23 (2015).

41. Lange, R. \& Hengge-Aronis, R. The nIpD gene is located in an operon with rpoS on the Escherichia coli chromosome and encodes a novel lipoprotein with a potential function in ceil wall formation. Mol. Microbiol. 13, 733-743 (1994).

42. Kojic, M. \& Venturi, V. Regulation of rpoS gene expression in Pseudomonas: involvement of a TetR family regulator. J. Bacteriol. 183, 3712-3720 (2001).

43. Rainey, P. B. \& Travisano, M. Adaptive radiation in a heterogeneous environment. Nature 394, 69-70 (1998).

44. Gómez, P. \& Buckling, A. Real-time microbial adaptive diversification in soil. Ecol. Lett. 16, 650-655 (2013).

45. Schippers, B., Bakker, A. W. \& Bakker, P. A. H. M. Interactions of deleterious and beneficial rhizosphere microorganisms and the effect of cropping practices. Ann. Rev. Phytopathol. 25, 339-358 (1987).
46. D'aes, J., De Maeyer, K., Pauwelyn, E. \& Höfte, M. Biosurfactants in plantPseudomonas interactions and their importance to biocontrol. Environ. Microbiol. Rep. 2, 359-372 (2010).

47. Yan, Q. et al. Secondary metabolism and interspecific competition affect accumulation of spontaneous mutants in the GacS-GacA regulatory system in Pseudomonas protegens. MBio 9, e01845-17 (2018).

48. Wei, X., Huang, X., Tang, L., Wu, D. \& Xu, Y. Global control of GacA in secondary metabolism, primary metabolism, secretion systems, and motility in the rhizobacterium Pseudomonas aeruginosa M18. J. Bacteriol. 195, 3387-3400 (2013).

49. O'Malley, M. R., Chien, C., Peck, S. C., Lin, N. \& Anderson, J. C. A revised model for the role of $\mathrm{GacS} / \mathrm{GacA}$ in regulating type III secretion by Pseudomonas syringae pv. tomato DC3000. Mol. Plant Pathol. 21, 139-144 (2020).

50. Houte, S. et al. Compost spatial heterogeneity promotes evolutionary diversification of a bacterium. J. Evol. Biol. https://doi.org/10.1111/jeb.13722 (2020).

51. Bakker, P. A. H. M., Pieterse, C. M. J., de Jonge, R. \& Berendsen, R. L. The soil-borne legacy. Cell 172, 1178-1180 (2018).

52. Klironomos, J. N. Feedback with soil biota contributes to plant rarity and invasiveness in communities. Nature 417, 67-70 (2002).

53. Kardol, P., Martijn Bezemer, T. \& van der Putten, W. H. Temporal variation in plant-soil feedback controls succession. Ecol. Lett. 9, 1080-1088 (2006).

54. Batstone, R. T., O'Brien, A. M., Harrison, T. L. \& Frederickson, M. E. Experimental evolution makes microbes more cooperative with their local host genotype. Science 370, 476-478 (2020).

55. Ramette, A. et al. Pseudomonas protegens sp. nov., widespread plant-protecting bacteria producing the biocontrol compounds 2,4-diacetylphloroglucinol and pyoluteorin. Syst. Appl. Microbiol. 34, 180-188 (2011).

56. Stutz, E. W., Défago, G. \& Kern, H. Naturally occurring fluorescent pseudomonads involved in suppression of black root rot of tobacco. Phytopathology 76, 181-185 (1986).

57. King, E. O., Ward, M. K. \& Raney, D. E. Two simple media for the demonstration of pyocyanin and fluorescin. J. Lab. Clin. Med. 44, 301-307 (1954).

58. Glickmann, E. \& Dessaux, Y. A critical examination of the specificity of the salkowski reagent for indolic compounds produced by phytopathogenic bacteria. Appl. Environ. Microbiol. 61, 793-796 (1995).

59. Alexander, D. B. \& Zuberer, D. A. Use of chrome azurol S reagents to evaluate siderophore production by rhizosphere bacteria. Biol. Fertil. Soils 12, 39-45 (1991).

60. Smeltzer, M. S., Hart, M. E. \& Iandolo, J. J. Phenotypic characterization of xpr, a global regulator of extracellular virulence factors in Staphylococcus aureus. Infect. Immun. 61, 919-925 (1993).

61. Oberhänsli, T., Défago, G. \& Haas, D. Indole-3-acetic acid (IAA) synthesis in the biocontrol strain CHA0 of Pseudomonas fluorescens: role of tryptophan side chain oxidase. Microbiology 137, 2273-2279 (1991).

62. Moskowitz, S. M., Foster, J. M., Emerson, J. \& Burns, J. L. Clinically feasible biofilm susceptibility assay for isolates of Pseudomonas aeruginosa from patients with cystic fibrosis. J. Clin. Microbiol. 42, 1915-1922 (2004).

63. Harrison, J. J. et al. Microtiter susceptibility testing of microbes growing on peg lids: a miniaturized biofilm model for high-throughput screening. Nat. Protoc. 5, 1236-1254 (2010).

64. Zamioudis, C., Mastranesti, P., Dhonukshe, P., Blilou, I. \& Pieterse, C. M. J. Unraveling root developmental programs initiated by beneficial Pseudomonas spp bacteria. Plant Physiol. 162, 304-318 (2013).

65. Højberg, O., Schnider, U., Winteler, H. V., Sørensen, J. \& Haas, D. Oxygensensing reporter strain of Pseudomonas fluorescens for monitoring the distribution of low-oxygen habitats in soil. Appl. Environ. Microbiol. 65, 4085-4093 (1999).

66. Pieterse, C. M. J. et al. Pseudomonas simiae WCS417: star track of a model beneficial rhizobacterium. Plant and Soil 1-19, https://doi.org/10.1007/ s11104-020-04786-9 (2020).

67. Millet, Y. A. et al. Innate immune responses activated in Arabidopsis roots by microbe-associated molecular patterns. Plant Cell 22, 973-990 (2010).

68. Hafner, M., Niepel, M., Chung, M. \& Sorger, P. K. Growth rate inhibition metrics correct for confounders in measuring sensitivity to cancer drugs. Nat. Methods 13, 521-527 (2016).

69. Tritt, A., Eisen, J. A., Facciotti, M. T. \& Darling, A. E. An integrated pipeline for de novo assembly of microbial genomes. PLoS ONE 7, e42304 (2012).

70. Seemann, T. Prokka: rapid prokaryotic genome annotation. Bioinformatics 30, 2068-2069 (2014)

71. Quinlan, A. R. \& Hall, I. M. BEDTools: a flexible suite of utilities for comparing genomic features. Bioinformatics 26, 841-842 (2010).

72. Kai Lee, H. et al. High-resolution melting approach to efficient identification and quantification of $\mathrm{H} 275 \mathrm{Y}$ mutant influenza H1N1/2009 virus in mixedvirus-population samples. J. Clin. Microbiol. 49, 3555-3559 (2011).

73. Zhong, W.-L. et al. Development of unlabeled probe based high-resolution melting analysis for detection of filaggrin gene mutation c.3321delA. J. Clin. Lab. Anal. 30, 892-896 (2016). 
74. Capper, R. L. et al. Quantitative high resolution melting: two methods to determine SNP allele frequencies from pooled samples. BMC Genet. 16, 62 (2015).

75. Jousset, A. et al. Predators promote defence of rhizosphere bacterial populations by selective feeding on non-toxic cheaters. ISME J. 3, 666-674 (2009).

76. Ross-Gillespie, A., Gardner, A., West, S. A. \& Griffin, A. S. Frequency dependence and cooperation: theory and a test with bacteria. Am. Nat. 170 331-342 (2007).

\section{Acknowledgements}

We thank Roy van der Meijs for his excellent work on the scopoletin sensitivity assays and Ke Yu, Roeland Berendsen and members of the Plant-Microbe Interactions Lab for helpful discussions. This work was supported by a China Scholarship Council fellowship (to E.L.) and a postdoctoral fellowship of the Research Foundation Flanders (FWO 12B8116RN) (to R.d.J.). V.-P.F. is funded by the Royal Society (RSG $\backslash R 1 \backslash 180213$ and CHL $\backslash$ R1 $\backslash 180031)$ and jointly by a grant from UKRI, Defra, and the Scottish Government, under the Strategic Priorities Fund Plant Bacterial Diseases programme (BB/T010606/1) at the University of York.

\section{Author contributions}

E.L., P.A.H.M.B., C.M.J.P. and A.J. designed the experiments. E.L., H.J. and C.L. performed the experiment. E.L., R.d.J., V.-P.F. and A.J. analysed the data. All authors collegially wrote the manuscript.

\section{Competing interests}

The authors declare no competing interests.

\section{Additional information}

Supplementary information The online version contains supplementary material available at https://doi.org/10.1038/s41467-021-24005-y.

Correspondence and requests for materials should be addressed to R.d.J., V.-P.F. or A.J. Peer review information Nature Communications thanks Rebecca Batstone, Catherine Masson-Boivin and the other, anonymous, reviewer(s) for their contribution to the peer review of this work. Peer reviewer reports are available.

Reprints and permission information is available at http://www.nature.com/ reprintsPublisher's note Springer Nature remains neutral with regard to jurisdictional claims in published maps and institutional affiliations.

\begin{abstract}
(c) (i) Open Access This article is licensed under a Creative Commons Attribution 4.0 International License, which permits use, sharing, adaptation, distribution and reproduction in any medium or format, as long as you give appropriate credit to the original author(s) and the source, provide a link to the Creative Commons license, and indicate if changes were made. The images or other third party material in this article are included in the article's Creative Commons license, unless indicated otherwise in a credit line to the material. If material is not included in the article's Creative Commons license and your intended use is not permitted by statutory regulation or exceeds the permitted use, you will need to obtain permission directly from the copyright holder. To view a copy of this license, visit http://creativecommons.org/ licenses/by/4.0/.
\end{abstract}

(C) The Author(s) 2021 